\title{
Segregaciones Escolares y Desigualdad de Oportunidades Educativas del Alumnado Extranjero en València
}

\author{
School Segregations and Inequality of Educational \\ Opportunities for Foreign Students in Valencia
}

\begin{abstract}
La segregación escolar, entendida como la distribución desigual de diversos grupos sociales en los centros escolares de un territorio, resulta de extraordinaria importancia para la equidad y la igualdad de oportunidades educativas de la población. Buena parte de los estudios sobre segregación escolar aproximan el fenómeno mediante el cálculo de índices que proporcionan una imagen general del sistema educativo en diferentes contextos territoriales, permitiendo hacer comparaciones entre ellos, pero no informan sobre las condiciones políticas o sociales de los contextos territoriales y educativos que puedan clarificar los factores condicionantes de los procesos de segregación. Este artículo analiza la segregación escolar del alumnado de origen extranjero en los centros escolares de la ciudad de València (España). El análisis relaciona los índices de segregación del conjunto del sistema, de los distritos de la ciudad y de la titularidad de los centros con datos de segregación residencial en el mismo territorio, con la distribución y características de los centros y con aproximaciones a las estrategias familiares. Los resultados sugieren múltiples procesos de segregación en los que las escuelas reflejan la segregación residencial de su entorno y emergen, además, segregaciones de carácter estrictamente escolar condicionadas por la política educativa, la selección de los centros escolares y la elección estratégica de las familias.
\end{abstract}

Descriptores: Segregación escolar; Educación básica; Oportunidades educativas; Mapa escolar; España.

\begin{abstract}
School segregation, understood as the unequal distribution of various social groups in the schools of a territory, is of extraordinary importance for the equity and equal educational opportunities of the population. A good part of the studies on school segregation approximate the phenomenon by calculating indices that provide a general image of the educational system in different territorial contexts, allowing comparisons between them, but they do not report on the political or social conditions of territorial and educational contexts that can clarify the conditioning factors of the segregation processes. This article analyses the school segregation of students of foreign origin in the schools of the city of Valencia (Spain). The analysis relates the segregation indices of the system as a whole, of the city districts and of the ownership of the centres with data from residential segregation in the same territory, with the distribution and characteristics of the centres, and with an approach to family strategies. The results suggest multiple processes of segregation in which the schools reflect the residential segregation of their surroundings and emerge, in addition, segregations of a strictly school nature conditioned by the educational policy, the selection of schools and the strategic choice of families.
\end{abstract}

Keywords: School segregation; Basic education; Educational opportunities; School mapping; Spain.

*Contacto: borja.madaria@uv.es

ISSN: $1696-4713$

www.rinace.net/reice/

revistas.uam.es/reice
Recibido: $\quad 27$ de abril 2020

$1^{\text {a }}$ Evaluación: 21 de junio 2020

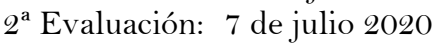

Aceptado: 15 de agosto 2020 


\section{Introducción}

Solemos considerar que uno de los pilares de la cohesión de nuestra sociedad es el carácter de 'ascensor social' del sistema escolar (Observatorio Social La Caixa, 2016), que ha facilitado el acceso a una educación de calidad a los sectores más desfavorecidos y ha mejorado sus oportunidades de movilidad social.

Sin embargo, la persistencia de la desigualdad en la escuela sufragada con fondos públicos cuestiona este carácter (Duru-Bellat, 2004; Holsinger y Jacob, 2008; Tenti Fanfani, 2008). Por ello, existe una larga tradición de investigación sobre la segregación escolar, entendida como la desigual distribución de los diversos grupos sociales en los centros escolares de un determinado territorio. El análisis de este fenómeno es muy importante para la implementación de políticas públicas ya que la distribución del alumnado y los procesos de elección de escuela tienen un peso relevante en la equidad de los sistemas escolares (Musset, 2012; Nusche, 2009).

Buena parte de los estudios abordan el fenómeno de la segregación escolar mediante el cálculo de índices que proporcionan una imagen general de los sistemas educativos en diferentes contextos territoriales (Alegre et al., 2008; Benito y González, 2007; Bonal 2012; Coleman et al., 1975; Guryam, 2004; Murillo, 2016; Murillo y Belavi, 2018; Murillo y Martínez-Garrido, 2018; Murillo, Martínez-Garrido y Belavi, 2017; Sánchez Hugalde, 2009), permitiendo hacer comparaciones entre ellos. Esos índices proporcionan una cuantificación de diferentes dimensiones de la segregación de los colectivos estudiados, pero no aportan datos ni pistas sobre las condiciones políticas o sociales de los contextos urbanos y educativos que permitan comprender las posibles causas de dichos procesos.

Otros estudios realizan aproximaciones cualitativas y etnográficas que informan de estas condiciones a través de experiencias particulares en casos concretos (Carrasco et al., 2009; Franze, 1998; García y Rubio, 2013). Sin embargo, son raros los que tratan de unificar ambas visiones y analizan en detalle la segregación en un único contexto territorial a escala sub-municipal.

Este artículo analiza las condiciones de segregación del alumnado de origen extranjero en los centros escolares de la ciudad de València, relacionando los índices de segregación del conjunto del sistema con los índices particulares de los diferentes distritos de la ciudad y de las diversas titularidades de los centros escolares. Al centrarnos en un contexto local completo, podemos relacionar los datos cuantitativos de la segregación escolar con los de su segregación residencial y con la diversa distribución, concentración, características y prestigio de sus escuelas.

\section{El estudio de la segregación escolar: antecedentes}

Existe cierto consenso en situar el origen de la investigación sobre la segregación escolar en 1954, cuando la Corte Suprema de los Estados Unidos declaró ilegal la segregación racial en las escuelas norteamericanas (Goodman, 1972, p. 276; Murillo y Belavi, 2018, p. 2; Reardon y Owens, 2014). Los primeros estudios analizaron los efectos de dicha sentencia en los procesos de desegregación o integración en la población afroamericana y midieron la aparente persistencia de la desigualdad entre blancos y negros (Coleman, 1975; Coleman et al., 1966; Katz, 1964). 
Algunos estudios confirman que hubo una rápida reducción de la segregación escolar en los distritos de población negra durante los años 60 y 70 del S. XX tras la citada declaración de ilegalidad (Coleman et al., 1966, p. 474; 1975, p. 51; Guryam, 2004, p. 924; Reber, 2005, p. 568), Sin embargo, otros sugieren que la segregación entre distritos escolares se incrementó a causa del proceso de huida de las familias blancas para evitar escuelas integradas (Coleman et al., 1975, p. 66; Farley et al., 1980; Rosell, 1976; Wilson, $1985)$.

El estudio de la segregación escolar se ha desarrollado de forma paralela a las investigaciones sobre la segregación residencial, y ha tomado los índices para medirla de ese campo de investigación. El carácter complejo y multidimensional de la segregación residencial generó un intenso debate sobre los instrumentos e indicadores más adecuados para su medición (Bell, 1954; Cowgill y Cowgill, 1951; Duncan y Duncan, 1955a), hasta que Massey y Denton (1988) fijaron cinco dimensiones en las que los diversos grupos sociales pueden estar segregados en el territorio y los índices más adecuados para medirlas.

Posteriormente, Gorard y Taylor (2002, p. 877) argumentaron que la Igualdad y la Exposición son las dos dimensiones de segregación que resultan más relevantes en el análisis de la segregación escolar. La dimensión de Igualdad se refiere a la uniformidad en la distribución de dos grupos sociales entre las diferentes áreas territoriales y el índice más utilizado para medirla es el índice de Disimilitud (Duncan y Duncan, 1955b). La dimensión de Exposición se define como la probabilidad de interacción entre miembros de los diferentes grupos sociales. El índice más extendido para medirla es el índice de Aislamiento (Bell, 1954).

El debate sobre estos índices no está cerrado y siguen surgiendo análisis críticos y nuevas propuestas que complementan y mejoran la medición de la segregación. Gorard y Taylor (2002) propusieron una alternativa al índice de Disimilitud que incrementa su estabilidad ante variaciones en el tamaño del grupo minoritario y, por tanto, proporciona tres utilidades inmediatas para el análisis específico de la segregación escolar (Murillo, 2016, p. 42). La primera es que permite comparar sistemas con diversos pesos del grupo minoritario estudiado, la segunda utilidad es que permite comparar la segregación de diferentes grupos presentes en un sistema, y la tercera, que permite analizar la evolución temporal de la segregación en un determinado sistema.

Por otra parte, Hutchens $(2001,2004)$ propuso el índice de la Raíz Cuadrada, que mide la dimensión de Igualdad mediante la suma del alejamiento de la igualdad distributiva de cada unidad analizada. El índice tiene la ventaja de que permite descomponer el valor global de segregación en la suma de la segregación dentro de las diferentes unidades estudiadas y la segregación que se produce entre ellas. Por ello, resulta adecuado para conocer la contribución a la segregación de las diferentes partes del sistema escolar (Murillo, 2016, p. 46).

Los análisis centrados en la cuantificación mediante índices abordan la desigual distribución y los efectos composicionales de la polarización a la que están sometidas las minorías, sin profundizar en el análisis del origen, las causas o los patrones sociales que provocan esa distribución desigual en el entorno. Desde finales de los años 80 del S. XX se ha prestado mayor atención a las condiciones estructurales y las políticas públicas, tanto de vivienda como educativas, que desembocan en la desigual distribución de los grupos sociales en el territorio y en las escuelas, reflexionando sobre las causas de la segregación, 
la exclusión, la pobreza y la construcción de la infraclase urbana (Jencks y Peterson, 1991; Massey, 1990; Massey y Denton, 1993; Wilson, 1987).

En España, el sistema educativo ha estado tradicionalmente dividido en escuelas para ricos y para pobres (Palacio y Ruiz, 1993; Vega Gil, 1997), y ha excluido al alumnado de etnia gitana (Fernández Enguita, 1999, p. 179; Grañeras et al., 1998, p. 136; Salinas Catalá, 2015; Santiago y Maya, 2012). Sin embargo, pese a la larga tradición de segregación socioeconómica y étnica, no fue hasta finales de la década de los años 90 del siglo XX cuando aparecen los primeros estudios sobre la segregación escolar en España (Carbonell, 1998; Essomba, 1999; Franze, 1998), a raíz del incremento de la inmigración de origen extranjero en muchos municipios españoles y las consecuencias de su desigual inserción escolar.

Desde entonces, los análisis específicos sobre segregación escolar se multiplicaron ante las primeras políticas municipales que pretendían dar respuesta al fenómeno (Alegre et al., 2008; Avilés, 2003; Benito y González, 2007; Bonal 2012; Carbonell et al., 2002; Carrasco et al., 2009; Colom, 2011, 2012; Murillo y Belavi, 2018; Murillo, Martínez-Garrido y Belavi, 2017; Sánchez Hugalde, 2009; Valiente, 2008).

Estas investigaciones propiciaron la incorporación de la segregación escolar a la agenda política y diversos organismos e instituciones a nivel local, regional y nacional han aportado nuevos estudios sobre el tema (Ayuntamiento de Vitoria-Gasteiz, 2016; Bonal, 2018; Bonal y Cuevas, 2019; Martínez y Ferrer, 2018; Síndic de Greuges de Catalunya, 2008, 2016a, 2016b; Tarabini et al., 2017), convirtiendo la segregación escolar en un tema de debate público más extendido.

Algunos autores han destacado la causalidad múltiple del fenómeno de la segregación escolar (García Castaño et al., 2012, p. 97) que se puede estructurar en cuatro grandes categorías temáticas (Valiente, 2008, p. 7). La primera, se centra en la influencia sobre la segregación escolar de la segregación residencial en los barrios donde están ubicadas las escuelas. Si bien se ha comprobado la relación entre ambos procesos, también se ha constatado que la segregación escolar suele ser más intensa que la residencial (Benito y González, 2007, p. 53; López-Falcón y Bayona, 2012, p. 23; Síndic de Greuges, 2016b, p. 12) y, además, que en un mismo contexto residencial coexisten centros escolares con distribuciones muy desiguales de la población extranjera (García y Rubio, 2013; Peláez, 2012).

La segunda categoría enfatiza que la administración tiene un impacto relevante en los procesos de segregación al implementar sus políticas educativas. En primer lugar, mediante la construcción de centros públicos y la ampliación o reducción de líneas en los existentes, pero también mediante los conciertos con centros privados. La aparición de nuevos centros en el territorio modifica las condiciones de oferta y demanda, resultando "estratégica en la distribución equilibrada del alumnado" (Bonal, 2018, p. 13), e incide en la capacidad de elección de las familias y en los criterios que utilizan para ello (Valiente, 2008, p. 3). La administración también influye mediante la delimitación de distritos escolares, la adscripción entre centros, y los criterios para la asignación de plazas en los centros escolares (Alegre et al., 2008, Olmedo y Andrada, 2008). Cualquier modificación en la zonificación o en el sistema de reparto de puntos puede alterar la composición del alumnado de los centros escolares y su rendimiento académico (Alegre, 2017, pp. 8-9; Murillo y Martínez-Garrido, 2018, p. 54), alterando su prestigio y su atractivo para las familias. La elaboración de ránquines de resultados escolares es otra medida que también 
tiene un gran impacto al visibilizar las desigualdades sociales subyacentes simplemente como diferencias de resultados académicos (Murillo y Martínez-Garrido, 2018, p. 55).

La tercera categoría de causas se centra en los mecanismos de selección del alumnado por parte de los centros educativos. Las empresas proveedoras de servicios escolares pueden influir en la escolarización mediante la construcción de prestigio a través de la 'selección adversa' del alumnado (Bonal, 2012, p. 23; Santiago y Maya, 2012, p. 25). Diversos autores han destacado la exigencia de pago de cuotas (Alegre et al., 2008), estrategias de disuasión del alumnado no deseado previas al proceso de matriculación (García y Rubio, 2013, p. 25) o la gestión de las reservas y vacantes tras el periodo ordinario de matrícula (Bonal, 2018, p. 13) como principales mecanismos de este proceso. Esta selección facilita mejores resultados académicos para ciertos centros (Coleman et al., 1966, p. 20; Dupriez, 2009, p. 9; Valiente, 2008, p. 8) que, por ello, reciben más solicitudes de plazas, aumentando sus posibilidades de elección del mejor alumnado (Allen y Vignoles, 2007, p. 643; Maroy, 2008, p. 7), incrementando las condiciones de segregación y legitimando la reproducción de las desigualdades (Bourdieu y Passeron, 1979).

Por último, la cuarta categoría destaca que el comportamiento de las familias también impacta en el proceso de distribución educativa desigual mediante la reacción estratégica a los criterios de selección de alumnado en función del prestigio percibido de las diferentes escuelas (Alegre et al., 2010) y las posibilidades de admisión en ellas. Ello implica mecanismos de huida de poblaciones autóctonas de determinados centros y distritos no deseados (Sánchez Hugalde, 2007, p. 18), o la elección estratégica de un centro escolar que maximice las posibilidades de admisión, aunque no sea el preferido (Benito y Gonzàlez, 2007, p. 22; Bonal, 2018, p. 15; Maroy, 2008, p. 6). También induce comportamientos de aproximación a los centros mejor considerados, mediante prácticas de movilidad residencial o mortgage school choice, tanto reales como ficticias (Bonal, 2018, p.15; Holme, 2002; Olmedo y Santa Cruz, 2008, p. 9).

La mayor parte de estos estudios han tomado como marco de estudio el ámbito nacional, autonómico, comarcal o municipal, pero los estudios enfocados en el ámbito sub-municipal son escasos. Algunos estudios han abordado barrios concretos en Madrid (Peláez, 2012) o en ciudades andaluzas como Almería y Granada (García y Rubio, 2012, 2013). Tan sólo conocemos estudios sistemáticos sobre las relaciones entre contexto territorial y segregación escolar para los distritos de una ciudad en Barcelona (López-Falcón y Bayona, 2012) y Santiago de Chile (Córdoba et al., 2017).

\section{Segregaciones del alumnado extranjero en València}

\subsection{Aproximación metodológica}

Durante buena parte del proyecto de investigación Mapa escolar de València (De Madaria et al., 2018; Rodríguez-Victoriano et al., 2018, 2019) no dispusimos de datos desagregados por centros escolares sobre ninguna de las variables usuales para abordar la segregación escolar. Ante la imposibilidad de analizar la desigual distribución de los grupos sociales en la red escolar de la ciudad, decidimos enfocar nuestros análisis preliminares en la desigualdad territorial de la estructura de oportunidades escolares que dicha red ofrece al alumnado. Este enfoque, casi casual, nos ha permitido abordar la segregación desde una perspectiva novedosa, relacionando los principales índices de las diversas dimensiones de segregación propuestos en la literatura con indicadores específicos que reflejan la 
desigualdad socioeconómica y de oportunidades educativas entre distritos, las estrategias familiares en la elección de centro y la distribución del alumnado extranjero en los distritos y centros escolares de la ciudad.

Con este objetivo, en la sección 3.2 caracterizamos la distribución de la población extranjera en los distritos de la ciudad, calculando los índices de su segregación residencial, en las dimensiones de desigualdad y aislamiento, y su relación con medidas de desigualdad socioeconómica entre distritos calculadas a partir de datos facilitados por la Oficina de Estadística del Ayuntamiento de València. Ello nos permite contextualizar el análisis de la segregación residencial en el marco de las desigualdades socioeconómicas presentes en el municipio.

En la sección 3.3 analizamos la desigualdad de oportunidades educativas en los distritos de València mediante el examen de la desigual distribución en la ciudad de la oferta, tanto de centros como de plazas escolares, con datos proporcionados por el Servicio de Educación del Ayuntamiento de València y la Consellería d'Educació de la Generalitat Valenciana. El análisis histórico y urbanístico de las desigualdades de oferta educativa en relación con la demanda potencial ilustra la base territorial de la segregación escolar.

A continuación, en la sección 3.4 aproximamos las estrategias familiares en la elección de centro a través de una caracterización del grado de atractivo de los distintos centros escolares a partir de los datos de admisión del curso 2016-2017 proporcionados por la Consellería d'Educació de la Generalitat Valenciana. De este modo, podemos ilustrar los distritos y centros con mayor y menor atractivo para las familias, y sus principales características.

En la sección 3.5 analizamos la situación real del alumnado extranjero matriculado en los centros de la ciudad y las relaciones entre su distribución residencial y su desigual presencia en los diversos centros escolares de cada distrito. De este modo se evidencian patrones de segregación escolar que trascienden la segregación residencial.

Finalmente, sobre las bases de conocimiento desarrolladas en las secciones anteriores, en la sección 3.6 abordamos el análisis de las segregaciones escolares del alumnado extranjero en los distritos de la ciudad de Valencia. Con este objetivo calculamos los índices específicos de segregación que captan las diversas dimensiones del fenómeno para cada distrito y titularidad. El resultado nos permite contextualizar el análisis de las segregaciones específicamente escolares en el marco de la segregación residencial y las desigualdades presentes en cada distrito de la ciudad.

\subsection{Contexto socioeconómico de los distritos de la ciudad}

El cuadro 1 refleja la distribución de la población, total y extranjera, residente en cada distrito, el porcentaje de población extranjera en ellos, el valor de los índices de segregación residencial en sus dimensiones de desigualdad y aislamiento, y dos medidas de desigualdad socioeconómica. La primera es la renta media según el IRPF, y la segunda, el valor de un índice socioeconómico sintético -ISS- (Rodríguez-Victoriano et al., 2018, p. 41) elaborado a partir de doce variables observables que proporciona una imagen de la condición socioeconómica prevalente en cada parte de la ciudad. La estructura jerárquica de la división territorial permite la agregación de los datos desde la sección censal, hasta el barrio y el distrito. Los resultados señalan que los distritos escolares que presentan un ISS muy alto en relación a la media se concentran todos en el centro de la ciudad mientras que dos tercios de los distritos periféricos tienen un ISS bajo o muy bajo. 
Cuadro 1. Datos de contexto de los distritos escolares de la ciudad de València

\begin{tabular}{|c|c|c|c|c|c|c|c|}
\hline & \multicolumn{2}{|c|}{ Población } & \multicolumn{3}{|c|}{ SEgr. REsidenc. } & \multicolumn{2}{|c|}{$\begin{array}{l}\text { ConTeXTo Socio- } \\
\text { ECONÓMICO }\end{array}$} \\
\hline & Total & Extranj. & $\begin{array}{c}\% \\
\text { extranj. }\end{array}$ & $\mathbf{G}$ & A & ISS & IRPF \\
\hline O1. Ciutat vella & 3,38 & 4,05 & 14,68 & 0,13 & 0,16 & 0,59 & 38300 \\
\hline o2. Eixample & 5,60 & 4,54 & 9,95 & 0,20 & 0,12 & 0,67 & 42645 \\
\hline 03. Extramurs & 6,29 & 5,72 & 11,14 & 0,16 & 0,13 & 0,54 & 35767 \\
\hline 04. Campanar & 4,92 & 4,66 & 11,62 & 0,17 & 0,14 & 0,51 & 35206 \\
\hline 05. Saïdia & 4,92 & 5,24 & 13,05 & 0,15 & 0,15 & 0,23 & 27893 \\
\hline o6. Pla del real & 4,64 & 3,59 & 9,49 & 0,16 & 0,11 & 0,73 & 48583 \\
\hline 07. L'olivereta & 6,09 & 7,66 & 15,42 & 0,15 & 0,18 & 0,13 & 24848 \\
\hline 08. Patraix & 6,82 & 4,63 & 8,33 & 0,18 & 0,10 & 0,42 & 29749 \\
\hline 09. Jesús & 7,57 & 7,87 & 12,75 & 0,17 & 0,15 & 0,24 & 26191 \\
\hline 10a. Quatre carreres-malilla & 2,77 & 1,82 & 8,06 & 0,13 & 0,09 & 0,30 & 28190 \\
\hline $\begin{array}{l}\text { 10b. Quatre carreres-av. } \\
\text { Plata }\end{array}$ & 6,29 & 7,79 & 15,20 & 0,12 & 0,17 & 0,30 & 26709 \\
\hline 11a. Poblats marítims-nord & 4,81 & 5,34 & 13,60 & 0,31 & 0,17 & 0,05 & 24206 \\
\hline 11b. Poblats marítims-sud & 1,43 & 1,98 & 16,91 & 0,15 & 0,19 & 0,05 & 24193 \\
\hline 12. Camins al grau & 8,23 & 9,46 & 14,10 & 0,15 & 0,16 & 0,37 & 31099 \\
\hline 13. Algirós & 5,73 & 4,81 & 10,31 & 0,17 & 0,13 & 0,44 & 32898 \\
\hline 14. Benimaclet & 4,19 & 3,95 & 11,58 & 0,23 & 0,15 & 0,41 & 31725 \\
\hline 15. Rascanya & 6,31 & 8,05 & 15,65 & 0,22 & 0,20 & 0,20 & 26573 \\
\hline 16. Benicalap & 5,57 & 5,67 & 12,48 & 0,17 & 0,15 & 0,20 & 26330 \\
\hline 17. Poblats del nord & 0,82 & 0,44 & 6,54 & 0,12 & 0,07 & 0,38 & 32804 \\
\hline 18. Poblats de l'oest & 1,77 & 1,56 & 10,84 & 0,11 & 0,12 & 0,10 & 23989 \\
\hline 19. Poblats del sud & 1,85 & 1,16 & 7,73 & 0,13 & 0,08 & 0,14 & 26224 \\
\hline Valencia & 100,00 & 100,00 & 12,26 & 0,19 & 0,15 & 0,35 & 30672 \\
\hline
\end{tabular}

Fuente: Elaboración propia a partir de datos del padrón municipal del Ajuntament de València en 2016 y el INE.

La población extranjera en la ciudad de València creció espectacularmente durante el boom económico de la primera década del S.XXI. Según los datos del padrón Municipal de Habitantes, el porcentaje de residentes extranjeros pasó de apenas el 1\% en 1996 hasta superar el $15 \%$ en 2009. Desde entonces, la proporción de población de origen extranjero ha descendido ligeramente hasta situarse en el 12\% en 2016. Tradicionalmente, los inmigrantes extranjeros han ocupado los barrios degradados de la ciudad, primero en el centro histórico y posteriormente asentándose en diversos distritos periféricos (Torres, 2007, pp. 74-77). Según el padrón de 2016, el 9\% de las secciones censales de la ciudad superaban el $20 \%$ de población extranjera, el 1\% superaban el 30\%, y tan sólo dos de las casi 600 secciones censales de la ciudad, el $0,17 \%$, tenía una concentración de población extranjera superior al 40\%. A nivel agregado, cuatro barrios de la ciudad superan el $20 \%$, tres se sitúan en distritos periféricos de condición socioeconómica baja o muy baja, mientras que sólo uno pertenece a un distrito de ISS muy alto.

Según estos datos, la condición socioeconómica de los distritos correlaciona inversamente con el porcentaje de población extranjera (coeficiente de correlación $r=-0,35$, coeficiente de determinación $\mathrm{R}^{2}=13 \%$ ), y correlacionan intensamente los pesos de la población total y extranjera en cada distrito de la ciudad $\left(r=0,92, \mathrm{R}^{2}=84 \%\right)$. Esto significa que la población extranjera se distribuye de modo similar al resto de la población por todos los 
distritos, con cierta tendencia a asentarse en entornos de condición socioeconómica más modesta.

Si analizamos los índices de desigualdad residencial de la distribución de población de origen extranjero en las distintas secciones censales de València, vemos que el índice de Gorard en el conjunto de la ciudad alcanza un valor de 0,19, que puede considerarse muy bajo. Tan solo cuatro distritos escolares (Poblats Marítims-Nord, Rascanya, Benimaclet y Eixample) y cuatro barrios (Creu Coberta, La Punta, La Roqueta y Tres Forques) tienen índices de segregación residencial superiores a esa cifra, y únicamente el distrito de Poblats Marítims-Nord, con 0,31, supera el valor de 0,30 que define una segregación de carácter medio.

Sin embargo, al analizar la dimensión de aislamiento observamos como el índice alcanza un valor de 0,15 para el conjunto de la ciudad, que puede considerarse medio. En esta dimensión únicamente tres distritos presentan índices bajos y el distrito escolar de Rascanya, con un valor del índice de 0,20, tiene un alto aislamiento residencial de la población de origen extranjero.

El porcentaje de población extranjera apenas correlaciona con el índice de segregación residencial en su dimensión de desigualdad $\left(r=0,19, \mathrm{R}^{2}=4 \%\right)$, pero correlaciona intensamente con la dimensión de aislamiento $\left(r=0,98, \mathrm{R}^{2}=96 \%\right)$. Ello significa que, en los distritos con más población extranjera, ésta se encuentra más aislada y concentrada en determinadas secciones censales.

\subsection{La desigualdad de oportunidades educativas en la ciudad de València}

Los datos que resumen la desigualdad de oportunidades educativas en infantil y primaria, reflejados respectivamente en los cuadros 2 y 3, han sido elaborados para informes anteriores de la presente investigación (Rodríguez-Victoriano et al., 2018; 2019). Se ha calculado la ratio de unidades escolares de titularidad pública por distrito, la ratio entre plazas ofertadas y demanda potencial en cada distrito escolar y el porcentaje de centros confesionales. A lo largo de nuestra investigación han aparecido indicios que sugieren que el tamaño del centro escolar pueda ser relevante en la elección de las familias, por lo que hemos incluido una variable que refleja el tamaño medio de los centros en cada distrito y por titularidades usando la media del número de líneas educativas de que consta cada centro escolar.

Cuadro 2. Características de la dotación escolar en Infantil de los distritos escolares de València 2017-18

\begin{tabular}{|c|c|c|c|c|c|c|}
\hline & \multicolumn{3}{|c|}{ Dotación } & \multicolumn{3}{|c|}{$\begin{array}{l}\text { TaMaño Medio. Líneas } \\
\text { Educativas Por CenTro }\end{array}$} \\
\hline & $\begin{array}{c}\text { Ratio de } \\
\text { plazas } \\
\text { públicas }\end{array}$ & $\begin{array}{l}\text { Ratio de } \\
\text { oferta y } \\
\text { demanda }\end{array}$ & $\begin{array}{c}\text { Ratio de } \\
\text { centros } \\
\text { religiosos }\end{array}$ & Con & Pub & Tot \\
\hline O1. Ciutat vella & 16,67 & 68,81 & 75,00 & 1,67 & 1,00 & 1,50 \\
\hline o2. Eixample & 32,61 & 99,57 & 40,00 & 1,57 & 1,67 & 1,60 \\
\hline 03. Extramurs & 29,51 & 122,39 & 50,00 & 2,14 & 2,00 & 2,10 \\
\hline O4. Campanar & 50,00 & 78,53 & 44,44 & 1,40 & 1,75 & 1,56 \\
\hline 05. Saïdia & 26,32 & 142,64 & 40,00 & 2,00 & 1,67 & 1,90 \\
\hline 06. Pla del real & 30,51 & 137,72 & 54,55 & 2,33 & 1,60 & 2,00 \\
\hline O7. L'olivereta & 42,11 & 130,89 & 42,86 & 1,57 & 1,14 & 1,36 \\
\hline 08. Patraix & 73,33 & 84,21 & 10,00 & 1,67 & 1,43 & 1,50 \\
\hline 09. Jesús & 66,04 & 84,29 & 15,38 & 1,20 & 1,50 & 1,38 \\
\hline
\end{tabular}




\begin{tabular}{lccc|ccc} 
10a. Quatre carreres-malilla & 62,50 & 92,31 & 0,00 & 1,50 & 1,67 & 1,60 \\
10b. Quatre carreres-av. Plata & 43,24 & 68,82 & 14,29 & 2,33 & 1,25 & 1,71 \\
11a. Poblats marítims-nord & 39,58 & 117,19 & 45,45 & 1,67 & 1,20 & 1,45 \\
11b. Poblats marítims-sud & 60,00 & 92,14 & 40,00 & 1,00 & 1,00 & 1,00 \\
12. Camins al grau & 54,17 & 91,14 & 23,08 & 2,20 & 1,63 & 1,85 \\
13. Algirós & 89,47 & 100,49 & 0,00 & 1,00 & 1,44 & 1,36 \\
14. Benimaclet & 65,38 & 88,27 & 40,00 & 1,50 & 2,00 & 1,80 \\
15. Rascanya & 47,50 & 63,09 & 25,00 & 2,33 & 1,40 & 1,75 \\
16. Benicalap & 43,90 & 70,06 & 28,57 & 1,75 & 2,00 & 1,86 \\
17. Poblats del nord & 100,00 & 129,31 & 0,00 & 0,00 & 1,50 & 1,50 \\
18. Poblats de l'oest & 60,00 & 90,14 & 33,33 & 2,00 & 1,50 & 1,67 \\
19. Poblats del sud & 87,50 & 156,25 & 20,00 & 1,00 & 1,75 & 1,60 \\
\hline Valencia & 49,52 & 95,97 & 31,21 & 1,77 & 1,51 & 1,63 \\
\hline
\end{tabular}

Fuente: Elaboración propia a partir de datos suministrados por el Ajuntament de València y la Consellería d'Educació.

Cuadro 3. Características de la dotación escolar en Primaria de los distritos escolares de València 2017-18

\begin{tabular}{|c|c|c|c|c|c|c|}
\hline & \multicolumn{3}{|c|}{ Dotación } & \multicolumn{3}{|c|}{$\begin{array}{l}\text { Tamaño Medio. Líneas } \\
\text { Educativas Por CEnTRo }\end{array}$} \\
\hline & $\begin{array}{l}\text { Ratio de } \\
\text { plazas } \\
\text { públicas }\end{array}$ & $\begin{array}{c}\text { Ratio de } \\
\text { oferta y } \\
\text { demanda }\end{array}$ & $\begin{array}{c}\text { Ratio de } \\
\text { centros } \\
\text { religiosos }\end{array}$ & Con & Pub & Tot \\
\hline O1. Ciutat vella & 16,28 & 87,83 & 80,00 & 1,75 & 1,00 & 1,60 \\
\hline 02. Eixample & 28,71 & 102,73 & 50,00 & 2,20 & 1,67 & 2,00 \\
\hline 03. Extramurs & 29,13 & 119,23 & 66,67 & 2,50 & 2,00 & 2,33 \\
\hline 04. Campanar & 29,91 & 104,25 & 66,67 & 2,00 & 1,67 & 1,89 \\
\hline 05. Saïdia & 27,59 & 135,51 & 40,00 & 2,00 & 1,67 & 1,90 \\
\hline 06. Pla del real & 31,58 & 130,38 & 55,56 & 2,60 & 1,50 & 2,11 \\
\hline 07. L'olivereta & 43,38 & 134,98 & 42,86 & 1,57 & 1,43 & 1,50 \\
\hline 08. Patraix & 73,03 & 72,45 & 11,11 & 2,00 & 1,43 & 1,56 \\
\hline 09. Jesús & 70,00 & 86,78 & 15,38 & 1,20 & 1,75 & 1,54 \\
\hline 10a. Quatre carreres-malilla & 63,27 & 86,21 & 0,00 & 1,50 & 1,67 & 1,60 \\
\hline 10b. Quatre carreres-av. Plata & 46,15 & 65,68 & 14,29 & 2,33 & 1,50 & 1,86 \\
\hline 11a. Poblats marítims-nord & 40,00 & 108,28 & 45,45 & 1,67 & 1,20 & 1,45 \\
\hline 11b. Poblats marítims-sud & 57,58 & 96,94 & 40,00 & 1,50 & 1,00 & 1,20 \\
\hline 12. Camins al grau & 53,55 & 87,14 & 23,08 & 2,40 & 1,63 & 1,92 \\
\hline 13. Algirós & 92,86 & 97,77 & 0,00 & 1,00 & 1,44 & 1,36 \\
\hline 14. Benimaclet & 66,67 & 86,26 & 40,00 & 1,50 & 2,00 & 1,80 \\
\hline 15. Rascanya & 53,33 & 67,06 & 25,00 & 2,33 & 1,40 & 1,75 \\
\hline 16. Benicalap & 46,15 & 72,30 & 28,57 & 1,75 & 2,00 & 1,86 \\
\hline 17. Poblats del nord & 100,00 & 96,57 & 0,00 & & 1,50 & 1,50 \\
\hline 18. Poblats de l'oest & 62,50 & 87,91 & 33,33 & 2,00 & 1,50 & 1,67 \\
\hline 19. Poblats del sud & 87,76 & 135,21 & 20,00 & 1,00 & 1,75 & 1,60 \\
\hline Valencia & 49,04 & 95,78 & 34,13 & 1,92 & 1,56 & 1,73 \\
\hline
\end{tabular}

Fuente: Elaboración propia a partir de datos suministrados por el Ajuntament de València y la Consellería d'Educació.

La ciudad de València ha sufrido una carencia histórica de escuelas de titularidad pública de calidad para atender a su población escolar (Fernández y Mayordomo, 1987, p. 74) y, 
como en el resto del estado español, se ha recurrido a las instituciones privadas para garantizar el derecho a la educación obligatoria de la ciudadanía. En los años finales de la dictadura franquista, el porcentaje de alumnado que se escolarizaba en las escuelas públicas de la ciudad era del 43\% (Instituto de Ciencias de la Educación, 1975, p. 59) a pesar del notable incremento de la oferta durante los años 40 y 60 del Siglo XX.

La figura 1 refleja cómo, tras la aprobación de Ley Orgánica Reguladora del Derecho a la Educación (LODE) en el año 1985, la dotación escolar de titularidad pública que proporcionaba la educación obligatoria en València se incrementó desde un 47\% hasta un $49 \%$ entre 1985 y 1990. Desde entonces, tras un retroceso en la primera mitad de los años 90, que dejó el porcentaje en el $46 \%$ en 1996, ha vuelto a crecer paulatinamente hasta recuperar en 2015 la misma ratio de plazas escolares públicas que había en la ciudad en 1990. La evolución de la educación infantil resulta más llamativa. La dotación pública en la ciudad ha disminuido desde una proporción del $56 \%$ en 1996, a una dotación del $30 \%$ en el año 2016. Esto se debe a la política de conciertos desarrollada por los gobiernos del Partido Popular que incrementó considerablemente el número de centros concertados en esta etapa.

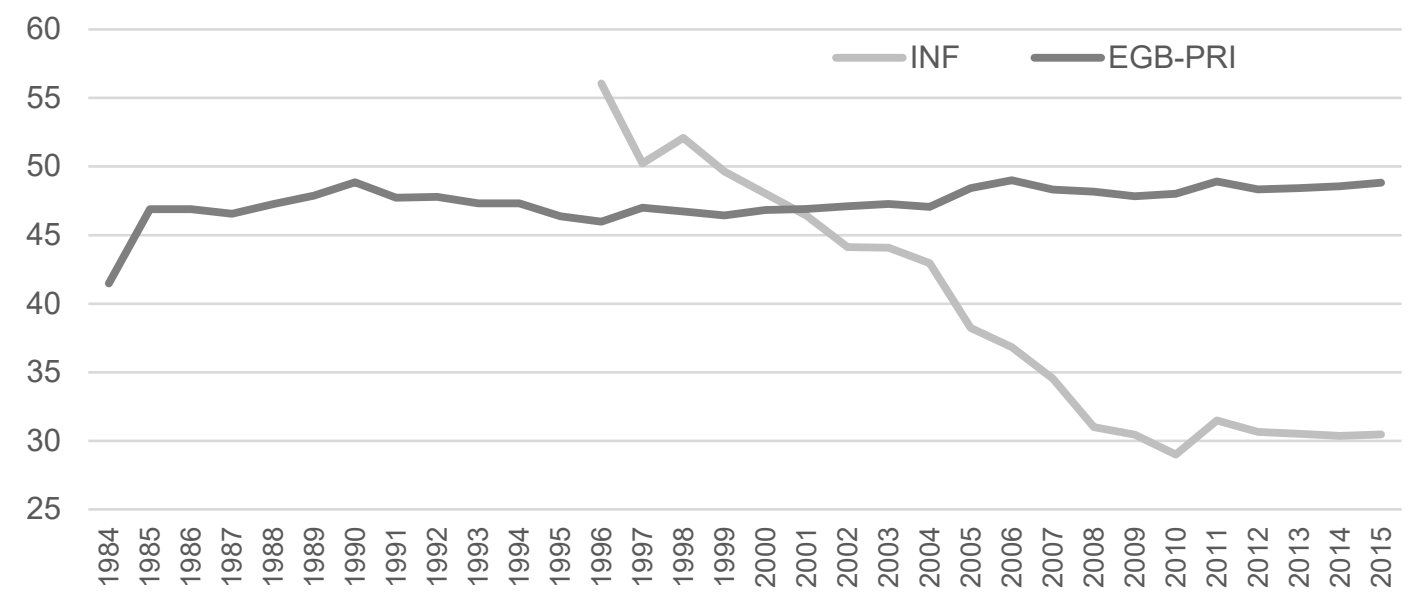

Figura 1. Evolución del porcentaje de unidades de titularidad pública en la red escolar de València

Fuente: Elaboración propia a partir de datos de la oficina de estadística del Ayuntamiento de Valencia.

Por otra parte, los centros escolares difieren entre sí en numerosos aspectos y están distribuidos de forma desigual en los distritos de la ciudad. La evolución histórica de València y la implantación de centros educativos en su territorio, ha ido conformando una red en la que los grandes centros escolares de prestigio, principalmente concertados regentados por órdenes religiosas, se han ubicado en los barrios centrales de la capital valenciana, entre los años 40 y 60 del siglo XX.

Por el contrario, en los barrios de la periferia predominan los centros escolares públicos, con presencia de centros concertados parroquiales y asistenciales. Fueron construidos en grandes grupos de vivienda social promovidos por diversas instituciones para satisfacer la demanda de la población desfavorecida, con un alto porcentaje de etnia gitana, que quedó sin hogar por las riadas que sufrió la ciudad en los años 1949 y 1957 (Ternes, 2010). Estos grupos de vivienda se han convertido con el paso del tiempo en los barrios con 
menor condición socioeconómica de la ciudad, se encuentran fuertemente estigmatizados y alojan los denominados 'centros gueto' (figura 2).

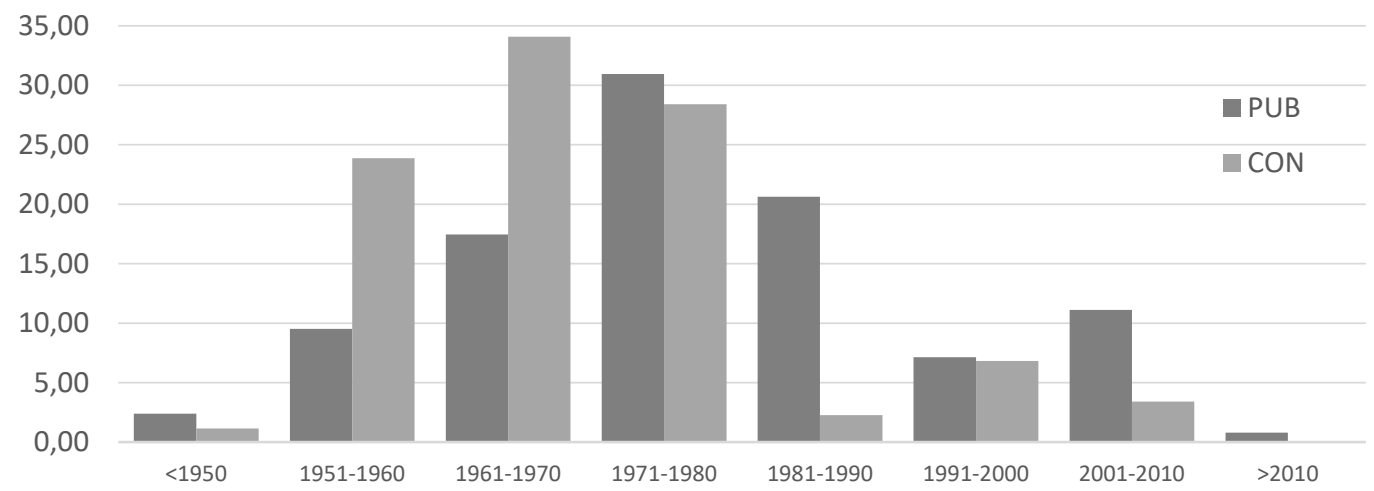

Figura 2. Distribución de centros en la ciudad de València por año de alta y titularidad Fuente: Elaboración propia a partir de datos suministrados por el Ajuntament de València.

Este proceso coincidió con un boom inmobiliario de promoción privada para albergar la masiva población inmigrante de procedencia rural que llegó a la ciudad en los años 60 y primeros 70 del siglo XX, que propició 'la gran transformación' (Alcala-Santaella et al., 2011, p. 203) de la ciudad mediante actuaciones de 'barraquismo vertical' (Teixidor, 2009, p. 88). Estos barrios se caracterizaron por construcciones de baja calidad y falta de equipamientos (Gaja, 1996, p. 81), por lo que los primeros centros escolares en asentarse en ellos fueron pequeñas academias de iniciativa privada que aprovecharon el nicho de mercado (Sanz, 1974, p. 404). Estos centros constituyen buena parte de la red de centros concertados laicos de la ciudad y siguen funcionando en locales ubicados en plantas bajas de edificios residenciales.

Durante los años 70 y 80 del siglo XX las diversas administraciones públicas realizaron un considerable esfuerzo por dotar de centros escolares públicos los barrios periféricos de la ciudad por lo que la red dual, con representaciones y prestigio social claramente contrapuesto, se mantiene en la actualidad. Los centros concertados religiosos tienden a concentrarse en distritos de condición socioeconómica muy alta o muy baja, acorde a su tradicional carácter de formación de las élites, por una parte, y a su vocación asistencial a los más desfavorecidos, por otra. Los centros concertados laicos lo hacen en distritos de tipo medio o bajo, compitiendo con los centros públicos que cubren mejor los distritos con ISS medio, bajo o muy bajo (figura 3).

La administración debe realizar la programación del sistema educativo, proporcionando la dotación escolar adecuada para satisfacer las necesidades de la población. Por tanto, la organización de los distritos escolares en la ciudad y la distribución de la oferta de plazas escolares en ellos deberían compensar las desigualdades de la implantación escolar en el territorio con el fin de garantizar el derecho a la educación en igualdad de condiciones para toda la ciudadanía. Sin embargo, el diseño de la zonificación escolar y la dotación de plazas escolares en la ciudad de València no ha modificado sustancialmente los desequilibrios presentes en el territorio (Rodríguez-Victoriano et al., 2018, p. 130). Un efecto constatable en el diseño de la zonificación escolar de la ciudad de València es un notable incremento de las condiciones de desigualdad residencial en el distrito de Poblats Marítims-Nord y un empeoramiento de las condiciones de aislamiento de Poblats 
Marítims-Sud, que constituye prácticamente un 'distrito escolar gueto', donde todos los centros escolares tienen bajo prestigio social.

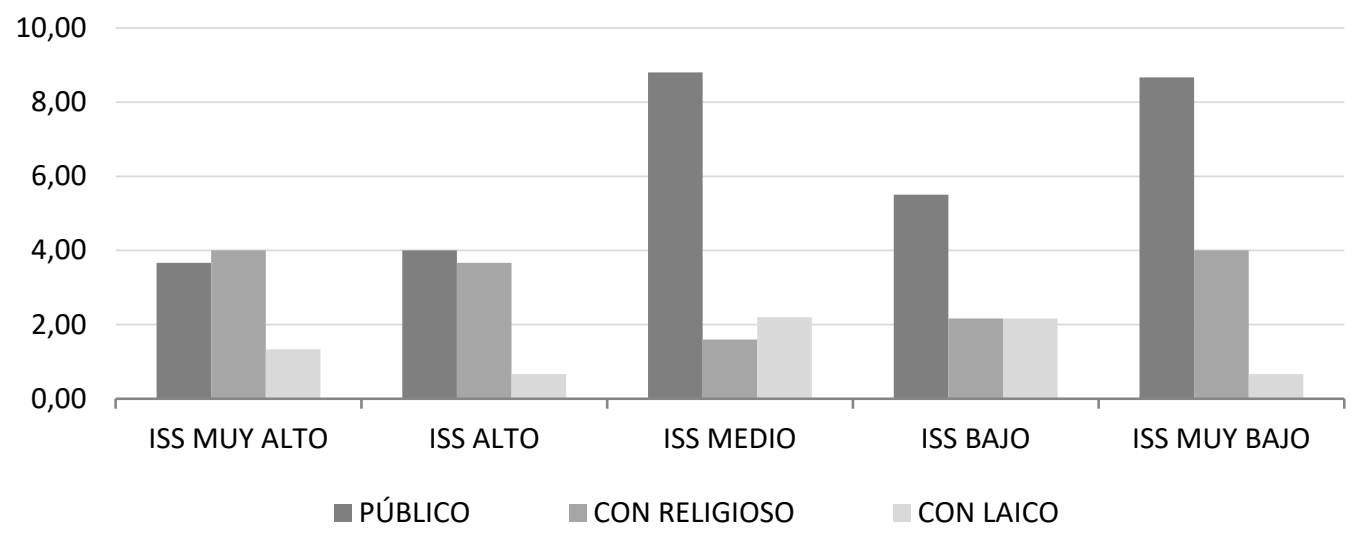

Figura 3. Distribución media de centros en la ciudad de València por titularidad e ISS Fuente: Elaboración propia a partir de datos suministrados por el Ajuntament de València.

Los datos indican que el porcentaje de escuela pública y el nivel socioeconómico del distrito están ligeramente relacionados $\left(r=-0,36, \mathrm{R}^{2}=13 \%\right)$. Los barrios más favorecidos cuentan con mayor dotación escolar, principalmente de carácter concertado religioso. En el curso escolar 2016-2017, la mayor parte de los distritos centrales de la ciudad tenía sobreoferta de plazas escolares en todas las etapas educativas. El conjunto de los seis distritos centrales de la ciudad presenta una sobreoferta del $12 \%$ en la segunda etapa de educación infantil y del $17 \%$ en la etapa de educación primaria. Por el contrario, los 13 distritos periféricos presentan una oferta escolar insuficiente para satisfacer su demanda de plazas escolares. Este déficit se sitúa en el $11 \%$ en educación infantil de segundo ciclo y el $13 \%$ en educación primaria.

La tipología de los centros también presenta relaciones con el contexto territorial. En los distritos más ricos, los centros tienen más líneas educativas $\left(r=0,55, \mathrm{R}^{2}=30 \%\right)$, de manera más acusada en los centros concertados. En la escuela concertada, también tienen más líneas educativas los colegios ubicados en el centro que los de la periferia, independientemente de su tamaño. Sin embargo, las instalaciones de los centros públicos tienden a ser más grandes en los distritos menos favorecidos y periféricos $\left(r=-0,44, \mathrm{R}^{2}=\right.$ $19 \%)$, aunque el número de líneas en ellos tiende a ser menor que en los del centro.

De este modo, se ha consolidado la estructura dual de la red escolar valenciana procedente del franquismo, en la que los grandes centros escolares de prestigio se encuentran en los barrios de nivel socioeconómico alto y los centros escolares desprestigiados, generalmente pequeños, se ubican en los barrios de condición más desfavorecida. Tal como hemos reflejado anteriormente (Rodríguez-Victoriano et al., 2018), el dibujo que nos ofrecen los datos es el de unos distritos centrales de la ciudad con una dotación baja de centros públicos y muy dotados de centros escolares privados con concierto educativo. Estos distritos escolarizan menos alumnado extranjero, cuentan con pocas vacantes $\mathrm{y}$, pese a tener una demanda potencial inferior a su oferta, son los distritos que alcanzan los índices más altos de ocupación al atraer alumnado de la periferia de la ciudad. Por el contrario, los distritos periféricos tienen un alumnado potencial mayor que el número de plazas escolares que ofertan, y ven como su población escolar emigra pese a que sus centros 
escolares tienen unos índices de ocupación menor. En general, el alumnado extranjero, las vacantes y los centros sometidos a procesos de estigmatización se concentran en estos distritos periféricos.

Este desequilibrio en la dotación escolar de los diferentes distritos de la ciudad genera tensiones y desajustes en el proceso de escolarización e incentiva movimientos del alumnado entre los diferentes distritos y centros educativos de la ciudad que propician dinámicas de segregación escolar.

\subsection{Las estrategias familiares en la elección de centro educativo}

Estudiar las estrategias familiares en la elección de centro educativo es complejo y requiere un análisis más minucioso que el realizado hasta ahora, y con enfoques de tipo cualitativo. No obstante, hemos elaborado un índice que aproxima el atractivo, deseabilidad o prestigio social de cada centro escolar y distrito a partir de los datos de admisión del curso 2016-2017 en el primer curso del segundo ciclo de educación infantil, que es el principal momento de acceso al sistema educativo español.

Cuadro 4. Atractivo de los centros escolares en os distritos escolares de la ciudad de València 2016-17

\begin{tabular}{|c|c|c|c|c|c|c|}
\hline & \multicolumn{3}{|c|}{$\begin{array}{c}\text { PORCENTAJE DE CENTROS } \\
\text { ESCOLARES POR } \\
\text { ATRACTIVO }\end{array}$} & \multicolumn{3}{|c|}{ ATRACTIVO MEDIO } \\
\hline & Alto & Medio & Bajo & Con & Pub & Tot \\
\hline O1. Ciutat vella & 0,00 & 100,00 & 0,00 & 1,15 & 0,73 & 1,05 \\
\hline o2. Eixample & 44,44 & 55,55 & 0,00 & 1,58 & 1,78 & 1,56 \\
\hline 03. Extramurs & 55,55 & 44,44 & 0,00 & 1,54 & 1,94 & 1,67 \\
\hline 04. Campanar & 11,11 & 44,44 & 44,44 & 0,74 & 1,27 & 0,97 \\
\hline 05. Saïdia & 30,00 & 50,00 & 20,00 & 1,32 & 1,14 & 1,26 \\
\hline 06. Pla del real & 50,00 & 30,00 & 20,00 & 2,15 & 1,35 & 1,83 \\
\hline 07. L'olivereta & 14,29 & 42,86 & 42,86 & 0,77 & 0,63 & 0,70 \\
\hline 08. Patraix & 30,00 & 30,00 & 40,00 & 0,91 & 1,03 & 0,99 \\
\hline 09. Jesús & 15,38 & 15,38 & 69,23 & 0,39 & 0,71 & 0,59 \\
\hline 10a. Quatre carreres-malilla & 10,00 & 80,00 & 10,00 & 0,96 & 0,93 & 0,94 \\
\hline 10b. Quatre carreres-av. Plata & 14,29 & 28,57 & 57,14 & 1,16 & 0,40 & 0,73 \\
\hline 11a. Poblats marítims-nord & 0,00 & 45,45 & 54,55 & 0,67 & 0,26 & 0,48 \\
\hline 11b. Poblats marítims-sud & 0,00 & 0,00 & 100,00 & 0,30 & 0,13 & 0,19 \\
\hline 12. Camins al grau & 30,77 & 53,85 & 15,38 & 1,47 & 0,99 & 1,17 \\
\hline 13. Algirós & 18,18 & 45,45 & 36,36 & 0,20 & 1,08 & 0,92 \\
\hline 14. Benimaclet & 0,00 & 80,00 & 20,00 & 1,26 & 1,01 & 1,11 \\
\hline 15. Rascanya & 25,00 & 25,00 & 50,00 & 1,35 & 0,48 & 0,81 \\
\hline 16. Benicalap & 14,29 & 42,86 & 42,86 & 1,11 & 0,69 & 0,93 \\
\hline \multicolumn{7}{|l|}{ 17. Poblats del nord } \\
\hline \multicolumn{7}{|l|}{ 18. Poblats de l'oest } \\
\hline \multicolumn{7}{|l|}{ 19. Poblats del sud } \\
\hline Valencia & 22,50 & 41,87 & 35,63 & 1,06 & 0,92 & 1,00 \\
\hline
\end{tabular}

Fuente: Elaboración propia a partir de datos suministrados por el Ajuntament de València y la Consellería d'Educació.

El índice consiste en el cociente entre el número de solicitudes de matrícula recibidas en cada centro y la media de solicitudes por centro en el conjunto de la ciudad. Con estos datos obtenemos el porcentaje de centros de alto (valor $>1,5$ ), medio (valor entre 0,5 y 
1,5) y bajo (valor $>0,5$ ) atractivo en cada distrito, y el atractivo total medio y por titularidad de cada uno de ellos, reflejados en cuadro 4.

Con todas las precauciones por la posible causalidad circular entre las variables, observamos una fuerte correlación entre la demanda de las familias y el nivel socioeconómico de los distritos $\left(\mathrm{r}=0,83, \mathrm{R}^{2}=68 \%\right)$ y el tamaño de los centros $(\mathrm{r}=0,84$, $\left.\mathrm{R}^{2}=70 \%\right)$. Las familias tienden a presentar más solicitudes de matrícula en los centros de mayor tamaño, con mayor probabilidad de ingreso, y en los distritos más ricos. Los porcentajes de escuela pública $\left(r=-0,41, \mathrm{R}^{2}=17 \%\right)$ y la ratio de oferta y demanda $(\mathrm{r}=$ 0,38, $\left.R^{2}=15 \%\right)$, también están relacionados con la demanda de las familias, aunque tienen una influencia menor. Ante la evidencia de que los centros más grandes están más solicitados por las familias, y que éstos se encuentran principalmente en los distritos más ricos, no resulta extraño que los centros más solicitados se encuentren en los distritos más ricos de la ciudad.

\subsection{La distribución del alumnado extranjero}

La distribución del alumnado extranjero en la segunda etapa de educación infantil y en la etapa de educación primaria en los distritos escolares de la ciudad se resume respectivamente en los cuadros 5 y 6 . Los datos muestran la participación del alumnado total y extranjero en cada distrito, la distribución del alumnado extranjero por titularidad en los diversos distritos, su concentración por centros para las diversas titularidades, y el rango de variación entre las concentraciones en cada titularidad y en el total de centros escolares.

En la ciudad de València se escolariza en las aulas de la escuela pública el $43-44 \%$ del alumnado del segundo ciclo de educación infantil y de educación primaria. Sin embargo, a ellas acude el $72 \%$ del alumnado de origen extranjero. Por el contrario, el $60 \%$ del alumnado de origen autóctono opta en ambas etapas por la escolarización en la escuela concertada.

Las personas de origen extranjero residentes en València suponen cerca del 12\% del total de la población y representan algo más el 10\% del alumnado de educación infantil y primaria escolarizado en los centros de la ciudad. Sin embargo, si observamos la concentración en ambas etapas de este alumnado en las diferentes escuelas, vemos cómo en las escuelas de titularidad pública la concentración asciende a casi el 17\%, y se sitúa en torno al $5 \%$ en la escuela concertada. Por tanto, las escuelas sufragadas con fondos públicos gestionadas por instituciones privadas están atendiendo a la mitad del alumnado extranjero que le correspondería para tener una distribución equilibrada del mismo.

Uno de los argumentos más utilizados para explicar esta circunstancia es que la población extranjera no se distribuye de modo uniforme en el territorio y la desigual concentración de este alumnado se debe a la diferente distribución de los colegios en los distintos distritos de la ciudad. Los datos indican que los índices de segregación residencial correlacionan con los de segregación escolar, tanto en su dimensión de desigualdad ( $\mathrm{r}=$ $\left.0,59, \mathrm{R}^{2}=34 \%\right)$ como en su dimensión de aislamiento $\left(\mathrm{r}=0,64, \mathrm{R}^{2}=41 \%\right)$, aunque explican poco más de un tercio de la variabilidad. 
Cuadro 5. Distribución del alumnado extranjero en Infantil en los distritos escolares de València 2017-18

\begin{tabular}{|c|c|c|c|c|c|c|c|c|c|c|}
\hline & \multicolumn{2}{|c|}{$\begin{array}{c}\text { PARTICIPACIÓN DEL } \\
\text { ALUMNADO }\end{array}$} & \multicolumn{2}{|c|}{$\begin{array}{l}\text { DISTRIBUCIÓN DEL } \\
\text { ALUMNADO } \\
\text { EXTRANJERO } \\
\end{array}$} & \multicolumn{3}{|c|}{$\begin{array}{l}\text { CONCENTRACIÓN DE ALUMNADO } \\
\text { EXTRANJERO POR CENTROS }\end{array}$} & \multicolumn{3}{|c|}{$\begin{array}{c}\text { RANGO DE LA VARIACIÓN DE } \\
\text { CONCENTRACIÓN DEL } \\
\text { ALUMNADO EXTRANJERO }\end{array}$} \\
\hline & Total & Extranjero & Con & Pub & Con & Pub & Tot & Con & Pub & Tot \\
\hline 01. Ciutat vella & 2,55 & 1,03 & 90,00 & 10,00 & 4,56 & 2,70 & 4,26 & 7,95 & & 7,95 \\
\hline o2. Eixample & 6,11 & 3,90 & 23,68 & 76,32 & 2,37 & 15,93 & 6,76 & 16,36 & 4,62 & 18,66 \\
\hline 03. Extramurs & 8,05 & 4,56 & 34,83 & 65,17 & 2,91 & 13,88 & 6,00 & 21,05 & 10,19 & 21,05 \\
\hline 04. Campanar & 5,36 & 4,51 & 44,32 & 55,68 & 7,56 & 10,40 & 8,92 & 33,33 & 19,97 & 33,33 \\
\hline 05. Saïdia & 7,28 & 7,07 & 57,97 & 42,03 & 7,91 & 17,58 & 10,28 & 32,23 & 28,85 & 36,36 \\
\hline 06. Pla del real & 7,25 & 4,46 & 27,59 & 72,41 & 2,46 & 17,45 & 6,51 & 7,80 & 45,81 & 53,13 \\
\hline 07. L'olivereta & 6,81 & 8,51 & 31,93 & 68,07 & 7,07 & 22,38 & 13,23 & 37,57 & 59,56 & 63,28 \\
\hline 08. Patraix & 5,84 & 3,08 & 10,00 & 90,00 & 1,52 & 7,94 & 5,58 & 0,47 & 14,29 & 15,97 \\
\hline 09. Jesús & 6,25 & 9,23 & 30,56 & 69,44 & 12,42 & 17,63 & 15,63 & 63,64 & 48,90 & 63,64 \\
\hline 10a. Quatre carreres-malilla & 2,96 & 2,51 & 22,45 & 77,55 & 4,53 & 12,54 & 8,97 & 5,21 & 35,10 & 38,41 \\
\hline 10b. Quatre carreres-av. Plata & 4,34 & 7,07 & 38,41 & 61,59 & 10,60 & 28,43 & 17,27 & 11,83 & 20,38 & 32,18 \\
\hline 11a. Poblats marítims-nord & 4,86 & 3,23 & 25,40 & 74,60 & 2,57 & 17,22 & 7,04 & 6,76 & 23,28 & 29,17 \\
\hline 11b. Poblats marítims-sud & 1,32 & 3,13 & 26,23 & 73,77 & 12,21 & 39,82 & 25,00 & 14,78 & 13,16 & 40,16 \\
\hline 12. Camins al grau & 8,23 & 9,84 & 29,17 & 70,83 & 6,97 & 19,05 & 12,66 & 19,32 & 68,18 & 70,20 \\
\hline 13. Algirós & 4,52 & 6,30 & 7,32 & 92,68 & 11,54 & 15,10 & 14,77 & 34,62 & 70,14 & 73,17 \\
\hline 14. Benimaclet & 3,33 & 1,95 & 5,26 & 94,74 & 0,84 & 9,55 & 6,19 & 1,25 & 22,32 & 22,32 \\
\hline 15. Rascanya & 5,24 & 8,10 & 12,03 & 87,97 & 3,33 & 35,19 & 16,36 & 23,73 & 18,23 & 44,62 \\
\hline 16. Benicalap & 4,58 & 7,84 & 42,48 & 57,52 & 12,36 & 27,76 & 18,15 & 21,03 & 32,76 & 39,74 \\
\hline 17. Poblats del nord & 0,92 & 0,15 & 0,00 & 100,00 & & 1,78 & 1,78 & & 0,06 & 0,06 \\
\hline 18. Poblats de l'oest & 1,44 & 1,85 & 44,44 & 55,56 & 10,39 & 17,86 & 13,53 & & 20,87 & 24,61 \\
\hline 19. Poblats del sud & 2,76 & 1,69 & 0,00 & 100,00 & 0,00 & 0,00 & 6,48 & & 14,60 & 17,31 \\
\hline Valencia & 100,00 & 100,00 & 30,09 & 69,91 & 5,72 & 16,70 & 10,59 & 63,64 & 73,17 & 73,17 \\
\hline
\end{tabular}

Fuente: Elaboración propia a partir de datos suministrados por la Consellería d'Educació. 
Cuadro 6. Distribución del alumnado extranjero en Primaria en los distritos escolares de València 2017-18

\begin{tabular}{|c|c|c|c|c|c|c|c|c|c|c|}
\hline & \multicolumn{2}{|c|}{$\begin{array}{l}\text { PARTICIPACIÓN DEL } \\
\text { ALUMNADO }\end{array}$} & \multicolumn{2}{|c|}{$\begin{array}{l}\text { DISTRIBUCIÓN DEL } \\
\text { ALUMNADO } \\
\text { EXTRANJERO } \\
\end{array}$} & \multicolumn{3}{|c|}{$\begin{array}{c}\text { CONCENTRACIÓN DE } \\
\text { ALUMNADO EXTRANJERO POR } \\
\text { CENTROS } \\
\end{array}$} & \multicolumn{3}{|c|}{$\begin{array}{c}\text { RANGO DE LA VARIACIÓN DE } \\
\text { CONCENTRACIÓN DEL ALUMNADO } \\
\text { EXTRANJERO } \\
\end{array}$} \\
\hline & Total & Extranjero & Con & Pub & Con & Pub & Tot & Con & Pub & Tot \\
\hline o1. Ciutat vella & 2,71 & 1,45 & 87,30 & 12,70 & 5,41 & 5,63 & 5,44 & 7,59 & & 7,59 \\
\hline 02. Eixample & 5,99 & 4,32 & 15,51 & 84,49 & 1,57 & 22,35 & 7,31 & 9,70 & 12,07 & 27,37 \\
\hline 03. Extramurs & 7,83 & 5,45 & 32,20 & 67,80 & 3,06 & 18,56 & 7,06 & 14,90 & 12,38 & 15,92 \\
\hline 04. Campanar & 6,43 & 5,66 & 60,82 & 39,18 & 7,40 & 13,10 & 8,92 & 33,29 & 29,63 & 34,00 \\
\hline 05. Saïdia & 6,96 & 6,40 & 54,51 & 45,49 & 6,77 & 17,07 & 9,33 & 31,80 & 27,07 & 37,05 \\
\hline 06. Pla del real & 7,20 & 3,53 & 20,26 & 79,74 & 1,38 & 14,79 & 4,98 & 4,30 & 30,59 & 37,89 \\
\hline 07. L'olivereta & 7,30 & 9,44 & 30,81 & 69,19 & 6,72 & 22,77 & 13,11 & 28,32 & 50,76 & 54,96 \\
\hline 08. Patraix & 5,07 & 3,00 & 6,92 & 93,08 & 1,30 & 8,21 & 6,00 & 0,71 & 18,45 & 20,14 \\
\hline 09. Jesús & 6,70 & 8,96 & 31,70 & 68,30 & 11,02 & 15,19 & 13,56 & 56,22 & 40,28 & 56,22 \\
\hline 10a. Quatre carreres-malilla & 3,39 & 2,12 & 21,74 & 78,26 & 3,94 & 7,65 & 6,35 & 1,51 & 24,44 & 24,44 \\
\hline 10b. Quatre carreres-av. Plata & 4,18 & 5,91 & 30,08 & 69,92 & 7,26 & 24,76 & 14,36 & 16,87 & 20,08 & 32,47 \\
\hline 11a. Poblats marítims-nord & 5,02 & 3,42 & 30,41 & 69,59 & 2,96 & 16,45 & 6,90 & 6,57 & 27,14 & 32,53 \\
\hline 11b. Poblats marítims-sud & 1,49 & 3,97 & 23,84 & 76,16 & 12,77 & 41,59 & 27,04 & 20,21 & 30,76 & 52,19 \\
\hline 12. Camins al grau & 8,24 & 9,33 & 23,51 & 76,49 & 5,04 & 18,89 & 11,48 & 16,61 & 50,17 & 54,68 \\
\hline 13. Algirós & 4,17 & 6,00 & 11,92 & 88,08 & 39,24 & 13,45 & 14,60 & & 48,46 & 48,46 \\
\hline 14. Benimaclet & 3,10 & 3,05 & 4,55 & 95,45 & 1,17 & 15,52 & 9,97 & 1,86 & 15,92 & 22,24 \\
\hline 15. Rascanya & 5,09 & 7,13 & 13,27 & 86,73 & 3,45 & 27,24 & 14,23 & 21,77 & 34,43 & 40,28 \\
\hline 16. Benicalap & 4,40 & 6,44 & 25,81 & 74,19 & 6,62 & 26,07 & 14,83 & 28,67 & 24,17 & 35,26 \\
\hline 17. Poblats del nord & 0,81 & 0,23 & 0,00 & 100,00 & & 2,90 & 2,90 & & $1, \mathrm{OO}$ & $1, \mathrm{OO}$ \\
\hline 18. Poblats de l'oest & 1,54 & 1,73 & 29,33 & 70,67 & 6,85 & 15,73 & 11,40 & & 13,49 & 18,40 \\
\hline 19. Poblats del sud & 2,37 & 2,45 & 1,89 & 98,11 & 1,20 & 12,32 & 10,50 & & 19,27 & 23,47 \\
\hline Valencia & 100,00 & 100,00 & 27,73 & 72,27 & 4,97 & 16,89 & 10,14 & 57,46 & 54,23 & 57,46 \\
\hline
\end{tabular}

Fuente: Elaboración propia a partir de datos suministrados por la Consellería d'Educació. 
Como hemos expuesto con anterioridad, la población extranjera en València se distribuye con relativa homogeneidad y de forma similar al conjunto de la población. La variación entre los distritos con mayor y menor población extranjera (Poblats Marítims-Sud con el $17 \%$, y Poblats del Nord con el 7\%) se sitúa en torno a los 10 puntos porcentuales. Por el contrario, al observar la diferencia entre la mayor y menor concentración de alumnado extranjero en los diferentes distritos escolares de València, observamos que la diferencia dobla esa cifra y supera los 23 puntos en la etapa de educación infantil, y los 24 en la educación primaria.

Si observamos las diferencias de concentración del alumnado extranjero en la escuela concertada y en la pública, vemos cómo se supera ampliamente esa diferencia en determinados distritos de la ciudad. En el segundo ciclo de educación infantil, la diferencia entre la concentración de alumnado extranjero entre las escuelas públicas y concertadas alcanza casi los 28 puntos porcentuales en el distrito de Poblats Marítims-Sud y los 32 en el de Rascanya. En la etapa de educación primaria, el distrito de Eixample presenta una diferencia de 21 puntos porcentuales, el de Rascanya se sitúa en 24, el de Algirós llega a los 26 y el de Poblats Marítims-Sud alcanza los 29. Todos ellos presentan un rango de variación muy superior a la media de la ciudad y a la de las concentraciones residenciales.

Al igual que ocurre en otras ciudades estudiadas, en casi todos los distritos de València la concentración de alumnado extranjero en la escuela pública es superior a la de la concertada y también a la concentración media en la ciudad. Únicamente el distrito central de Ciutat Vella, cuyo único centro público tiene como lengua vehicular el Valenciano, cuenta con un mayor porcentaje de alumnado extranjero en la escuela concertada.

Es importante destacar que la desigualdad no se produce únicamente entre las dos titularidades. La diferencia en la concentración de alumnado extranjero entre los diversos centros de la ciudad es similar. En los centros de titularidad pública oscila entre el $0 \%$ y el $73 \%$ en educación infantil, y entre el 1,5\% y el 56\% en educación primaria. En la escuela concertada, varía entre el $0 \%$ y el $67 \%$ en educación infantil y el $0 \%$ y el $57 \%$ en educación primaria. La principal diferencia, como indican las figuras 4 y 5 , radica en cómo se distribuyen los centros según su concentración de alumnado extranjero.

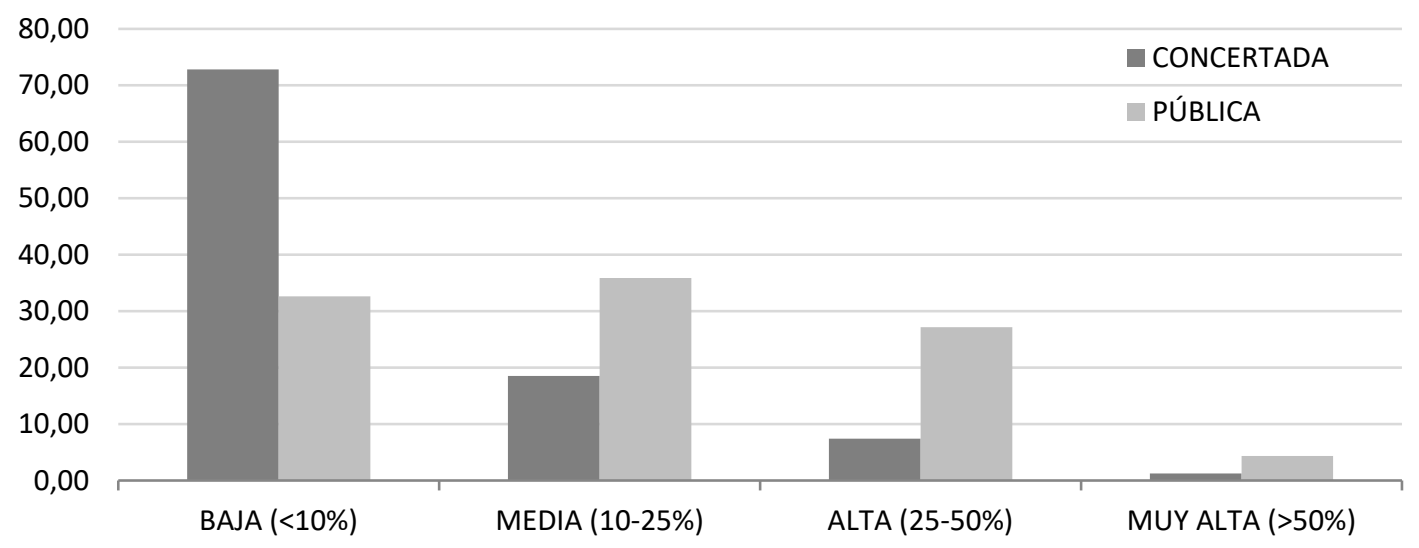

Figura 4. Centros de Educación Infantil en València por concentración de alumnado extranjero y titularidad

Fuente: Elaboración propia a partir de datos suministrados por la Consellería d'Educació de la Generalitat Valenciana. 
En educación infantil, más del $70 \%$ de centros concertados tienen una baja concentración de alumnado extranjero. La mitad no supera el 5\% y el 20\% no alcanzan siquiera el $1 \%$. Trece centros concertados no escolarizaban alumnado de origen extranjero pese a encontrarse, en algún caso, en barrios con alta concentración de ese tipo de población. En la escuela de titularidad pública, los centros se encuentran similarmente distribuidos entre baja, media y alta concentración.

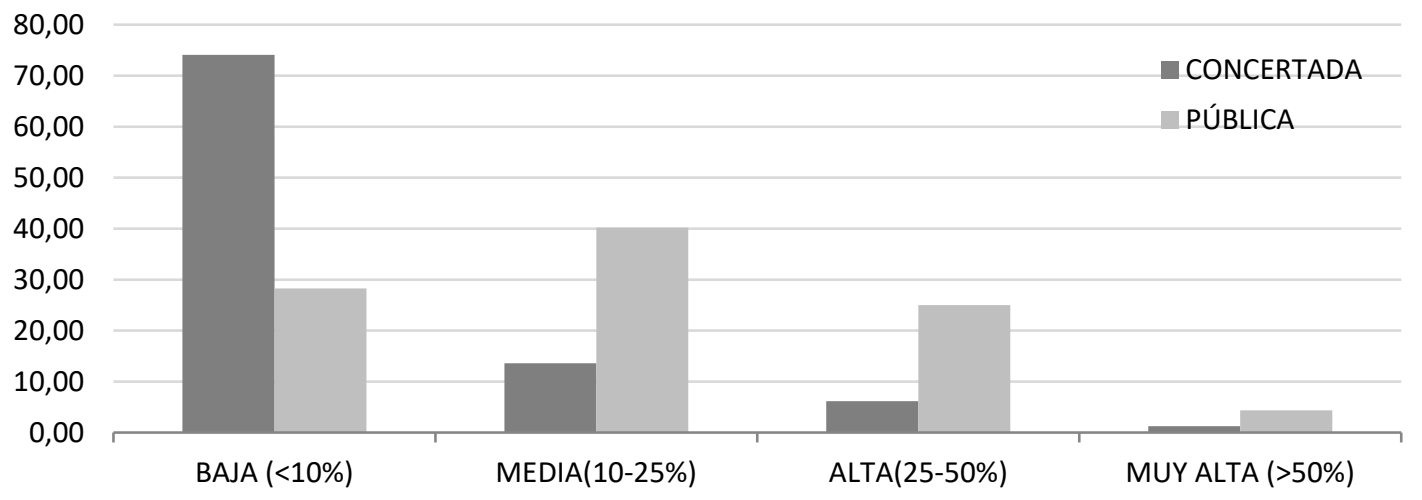

Figura 5. Centros de Educación Primaria en València por concentración de alumnado extranjero y titularidad

Fuente: Elaboración propia a partir de datos suministrados por la Consellería d'Educació de la Generalitat Valenciana.

En educación primaria, las distribuciones son muy similares, el $68 \%$ de los centros concertados no supera el 5\% de concentración de alumnado extranjero y el $19 \%$ no alcanzan el $1 \%$. Como ocurre en la etapa anterior, seis centros concertados no escolarizaban a ningún alumno o alumna de origen extranjero aún situándose en barrios con alta concentración de ese tipo de población. En la escuela pública predominan los centros de concentración media.

También se observan diferencias dentro de la escuela concertada entre los centros de carácter confesional cristiano y los que se declaran laicos. Éstos tienen una concentración de alumnado extranjero del $7 \%$ en educación infantil y del $8 \%$ en primaria, cifras que son un $30 \%$ inferior a la media de la ciudad. Por el contrario, los centros religiosos, tienen unos porcentajes del $5 \%$ y $4 \%$ en ambas etapas, inferiores a la mitad de la concentración media del alumnado extranjero de la ciudad. Dentro de las escuelas laicas, la mayor concentración se produce en centros gestionados por cooperativas o fundaciones, con el 10-11\% en ambas etapas, similares a la media; frente a centros gestionados por sociedades mercantiles, donde las concentraciones se sitúan alrededor del 6\%. Entre los colegios de carácter religioso la mayor concentración de alumnado extranjero se produce en los centros diocesanos, con el 10-12\% de alumnado extranjero en sus aulas en las dos etapas, frente a los centros gestionados por fundaciones u órdenes religiosas y sociedades mercantiles, que oscilan entre el $3 \%$ y el $6 \%$.

Además de las diferencias por titularidad, los datos nos indican que el porcentaje de alumnado extranjero es menor en los centros más grandes y mayor en aquellos centros menos demandados por las familias y que, por tanto, cuentan con mayor número de vacantes. El porcentaje de alumnado extranjero en los centros correlaciona negativamente con los porcentajes de centros de alta $\left(r=-0,37, R^{2}=13 \%\right)$ y media $\left(r=-0,60, R^{2}=36 \%\right)$ 
demanda familiar en cada distrito. Por el contrario, correlaciona positivamente con el porcentaje de centros de baja demanda familiar $\left(r=0,78, \mathrm{R}^{2}=60 \%\right)$.

\subsection{Segregaciones escolares del alumnado de origen extranjero en Valencia}

Los datos del alumnado extranjero matriculado en los centros escolares permiten calcular los índices de segregación escolar de Disimilitud, de Gorard, de Aislamiento y de Hutchens para cada distrito escolar y titularidad, cuyos valores se recogen en el cuadro 7 para la etapa de educación infantil y en el cuadro 8 para la etapa de educación primaria.

La distribución del alumnado extranjero en los diversos centros educativos de València determina, con carácter general, valores relativamente elevados de todos los índices de segregación escolar considerados. El índice de Disimilitud alcanza valores cercanos al 0,5 tanto en la etapa de educación infantil como en la de primaria para el conjunto de la ciudad en el curso 2017-2018. Estas cifras significan que habría que cambiar de centro casi a la mitad del alumnado en ambas etapas para conseguir que su distribución estuviera equilibrada entre todos los centros escolares de la ciudad.

Si analizamos el valor de los índices para las dos titularidades, observamos que la desigualdad es superior en la escuela concertada en la mayoría de distritos de la ciudad. En la etapa de infantil, el índice alcanza el 0,51, frente al 0,39 de la escuela pública, y en la etapa de primaria, el 0,48 frente al 0,35. El índice de aislamiento revela que la probabilidad del alumnado de origen extranjero de relacionarse únicamente con alumnos y alumnas de su misma condición es del $25 \%$ en educación infantil y del $23 \%$ en primaria. En ambos casos, el valor del índice de aislamiento se puede considerar elevado. El valor del índice se sitúa en 0,26 y 0,28 en la escuela pública, mientras que en la escuela concertada desciende a 0,17 y 0,18 , valores considerados medios.

Sin embargo, para analizar las contribuciones de cada uno de los sectores a la segregación total es más adecuado utilizar el índice de segregación de Hutchens. Al descomponer dicho índice, vemos que la segregación dentro de la red de cada titularidad es siempre superior a la segregación entre ambas, y que la contribución de ambas a la segregación total es similar. La contribución de la escuela pública es ligeramente superior en la etapa de educación infantil, y la de la escuela concertada es superior en la educación primaria. Al analizar mediante este índice la contribución de la escuela concertada religiosa y laica a la segregación, observamos cómo en torno al 75\% de la segregación dentro de las escuelas concertadas se debe a los centros de titularidad religiosa. 
Cuadro 7. Índices de segregación del alumnado extranjero en Infantil en los distritos escolares de València

\begin{tabular}{|c|c|c|c|c|c|c|c|c|c|c|c|c|c|c|}
\hline & \multicolumn{3}{|c|}{ DISIMILITUD } & \multicolumn{3}{|c|}{ GORARD } & \multicolumn{3}{|c|}{ AISLAMIENTO } & \multicolumn{5}{|c|}{ HUTCHENS } \\
\hline & Con. & Pub. & Tot. & Con. & Pub. & Tot. & Con. & Pub. & Tot. & Hcon & Hpub & Hintra & Hinter & Htotal \\
\hline O1. Ciutat vella & 0,30 & 0,00 & 0,29 & 0,28 & 0,00 & 0,28 & 0,07 & 0,03 & 0,06 & 0,19 & 0,00 & 0,19 & 0,04 & 0,22 \\
\hline 02. Eixample & 0,46 & 0,07 & 0,55 & 0,45 & 0,06 & 0,51 & 0,09 & 0,16 & 0,15 & 0,15 & 0,04 & 0,19 & 0,25 & 0,44 \\
\hline 03. Extramurs & 0,46 & 0,15 & 0,53 & 0,44 & 0,13 & 0,50 & 0,12 & 0,15 & 0,14 & 0,24 & 0,06 & 0,31 & 0,18 & 0,48 \\
\hline 04. Campanar & 0,64 & 0,23 & 0,44 & 0,59 & 0,20 & 0,40 & 0,24 & 0,14 & 0,18 & 0,24 & 0,11 & 0,36 & 0,00 & 0,36 \\
\hline 05. Saïdia & 0,46 & 0,25 & 0,44 & 0,42 & 0,21 & 0,39 & 0,19 & 0,23 & 0,15 & 0,32 & 0,08 & 0,40 & 0,04 & 0,43 \\
\hline 06. Pla del real & 0,50 & 0,26 & 0,42 & 0,48 & 0,21 & 0,42 & 0,06 & 0,26 & 0,20 & 0,21 & 0,12 & 0,32 & 0,14 & 0,47 \\
\hline 07. L'olivereta & 0,49 & 0,37 & 0,51 & 0,45 & 0,29 & 0,44 & 0,18 & 0,37 & 0,31 & 0,23 & 0,19 & 0,41 & 0,09 & 0,50 \\
\hline 08. Patraix & 0,07 & 0,15 & 0,32 & 0,07 & 0,13 & 0,30 & 0,02 & 0,09 & 0,09 & 0,01 & 0,11 & 0,12 & 0,17 & 0,30 \\
\hline 09. Jesús & 0,71 & 0,48 & 0,57 & 0,62 & 0,39 & 0,48 & 0,51 & 0,32 & 0,38 & 0,23 & 0,29 & 0,52 & 0,00 & 0,52 \\
\hline 10a. Q. Carreres-malilla & 0,22 & 0,42 & 0,35 & 0,21 & 0,37 & 0,32 & 0,06 & 0,25 & 0,21 & 0,07 & 0,30 & 0,37 & 0,02 & 0,40 \\
\hline 10b. Q. Carreres-av. Plata & 0,29 & 0,17 & 0,15 & 0,26 & 0,12 & 0,12 & 0,14 & 0,30 & 0,24 & 0,15 & 0,08 & 0,23 & 0,06 & 0,29 \\
\hline 11a. Pob. Marítims-nord & 0,26 & 0,35 & 0,49 & 0,25 & 0,29 & 0,46 & 0,04 & 0,23 & 0,19 & 0,10 & 0,15 & 0,25 & 0,24 & 0,49 \\
\hline 11b. Pob. Marítims-sud & 0,34 & 0,10 & 0,21 & 0,30 & 0,06 & 0,16 & 0,17 & 0,41 & 0,34 & 0,13 & 0,06 & 0,19 & 0,14 & 0,34 \\
\hline 12. Camins al grau & 0,50 & 0,41 & 0,50 & 0,47 & 0,33 & 0,44 & 0,15 & 0,32 & 0,27 & 0,20 & 0,22 & 0,42 & 0,06 & 0,48 \\
\hline 13. Algirós & 0,75 & 0,46 & 0,48 & 0,67 & 0,39 & 0,41 & 0,35 & 0,35 & 0,35 & 0,04 & 0,44 & 0,48 & 0,00 & 0,48 \\
\hline 14. Benimaclet & 0,33 & 0,44 & 0,51 & 0,32 & 0,40 & 0,48 & 0,01 & 0,17 & 0,16 & 0,03 & 0,28 & 0,30 & 0,12 & 0,42 \\
\hline 15. Rascanya & 0,66 & 0,14 & 0,60 & 0,63 & 0,09 & 0,50 & 0,18 & 0,36 & 0,34 & 0,14 & 0,07 & 0,21 & 0,21 & 0,42 \\
\hline 16. Benicalap & 0,24 & 0,36 & 0,35 & 0,21 & 0,26 & 0,29 & 0,16 & 0,36 & 0,28 & 0,13 & 0,16 & 0,29 & 0,07 & 0,36 \\
\hline 17. Poblats del nord & & 0,01 & 0,01 & 0,00 & 0,01 & 0,01 & & 0,02 & 0,02 & & 0,01 & 0,01 & 0,00 & 0,01 \\
\hline 18. Poblats de l'oest & 0,00 & 0,21 & 0,16 & 0,00 & 0,17 & 0,13 & 0,10 & 0,21 & 0,17 & 0,00 & 0,11 & 0,11 & 0,06 & 0,17 \\
\hline 19. Poblats del sud & 0,00 & 0,37 & 0,41 & 0,00 & 0,34 & 0,39 & 0,00 & 0,12 & 0,12 & 0,00 & 0,33 & 0,33 & 0,03 & 0,36 \\
\hline Valencia & 0,51 & 0,39 & 0,49 & 0,48 & 0,33 & 0,44 & 0,18 & 0,28 & 0,25 & 0,20 & 0,21 & 0,41 & 0,05 & 0,46 \\
\hline
\end{tabular}

Fuente: Elaboración propia a partir de datos suministrados por la Consellería d’Educació. 
Cuadro 8. Índices de segregación del alumnado extranjero en Primaria en los distritos escolares de València

\begin{tabular}{|c|c|c|c|c|c|c|c|c|c|c|c|c|c|c|}
\hline & \multicolumn{3}{|c|}{ DISIMILITUD } & \multicolumn{3}{|c|}{ GORARD } & \multicolumn{3}{|c|}{ AISLAMIENTO } & \multicolumn{5}{|c|}{ HUTCHENS } \\
\hline & Con. & Pub. & Tot. & Con. & Pub. & Tot. & Con. & Pub. & Tot. & Hcon & Hpub & Hintra & Hinter & Htotal \\
\hline O1. Ciutat vella & 0,20 & 0,00 & 0,17 & 0,19 & 0,00 & 0,16 & 0,07 & 0,06 & 0,07 & 0,14 & 0,00 & 0,14 & 0,00 & 0,14 \\
\hline 02. Eixample & 0,47 & 0,16 & 0,63 & 0,46 & 0,13 & 0,59 & 0,05 & 0,24 & 0,21 & 0,14 & 0,07 & 0,21 & 0,33 & 0,53 \\
\hline 03. Extramurs & 0,31 & 0,14 & 0,52 & 0,30 & 0,12 & 0,48 & 0,07 & 0,20 & 0,16 & 0,17 & 0,06 & 0,22 & 0,28 & 0,50 \\
\hline O4. Campanar & 0,39 & 0,34 & 0,42 & 0,36 & 0,29 & 0,38 & 0,18 & 0,21 & 0,19 & 0,28 & 0,11 & 0,39 & 0,05 & 0,44 \\
\hline 05. Saïdia & 0,45 & 0,24 & 0,43 & 0,42 & 0,20 & 0,39 & 0,17 & 0,22 & 0,13 & 0,31 & 0,08 & 0,39 & 0,03 & 0,42 \\
\hline 06. Pla del real & 0,47 & 0,22 & 0,46 & 0,46 & 0,19 & 0,47 & 0,03 & 0,20 & 0,17 & 0,17 & 0,10 & 0,27 & 0,24 & 0,50 \\
\hline O7. L'olivereta & 0,54 & 0,28 & 0,46 & 0,50 & 0,22 & 0,40 & 0,16 & 0,31 & 0,26 & 0,22 & 0,14 & 0,36 & 0,05 & 0,41 \\
\hline 08. Patraix & 0,10 & 0,30 & 0,40 & 0,10 & 0,27 & 0,37 & 0,01 & 0,12 & 0,11 & 0,02 & 0,23 & 0,25 & 0,14 & 0,39 \\
\hline o9. Jesús & 0,61 & 0,46 & 0,52 & 0,54 & 0,39 & 0,45 & 0,39 & 0,26 & 0,30 & 0,23 & 0,28 & 0,52 & 0,00 & 0,52 \\
\hline 10a. Q. Carreres-malilla & 0,09 & 0,42 & 0,35 & 0,08 & 0,39 & 0,33 & 0,04 & 0,17 & 0,14 & 0,02 & 0,31 & 0,33 & 0,04 & 0,38 \\
\hline 10b. Q. Carreres-av. Plata & 0,38 & 0,21 & 0,22 & 0,35 & 0,16 & 0,19 & 0,12 & 0,27 & 0,23 & 0,17 & 0,10 & 0,27 & 0,09 & 0,35 \\
\hline 11a. Pob. Marítims-nord & 0,32 & 0,31 & 0,44 & 0,31 & 0,26 & 0,41 & 0,04 & 0,22 & 0,17 & 0,14 & 0,13 & 0,27 & 0,16 & 0,43 \\
\hline 1 1b. Pob. Marítims-sud & 0,45 & 0,21 & 0,22 & 0,40 & 0,12 & 0,16 & 0,21 & 0,45 & 0,40 & 0,16 & 0,12 & 0,28 & 0,07 & 0,34 \\
\hline 12. Camins al grau & 0,50 & 0,37 & 0,47 & 0,47 & 0,30 & 0,42 & 0,12 & 0,30 & 0,26 & 0,18 & 0,22 & 0,40 & 0,06 & 0,45 \\
\hline 13. Algirós & 0,00 & 0,36 & 0,37 & 0,00 & 0,31 & 0,32 & 0,39 & 0,23 & 0,25 & 0,00 & 0,33 & 0,33 & 0,04 & 0,37 \\
\hline 14. Benimaclet & 0,35 & 0,18 & 0,42 & 0,35 & 0,15 & 0,38 & 0,02 & 0,18 & 0,17 & 0,05 & 0,13 & 0,18 & 0,17 & 0,35 \\
\hline 15. Rascanya & 0,68 & 0,17 & 0,57 & 0,66 & 0,12 & 0,49 & 0,18 & 0,31 & 0,29 & 0,15 & 0,08 & 0,24 & 0,18 & 0,42 \\
\hline 16. Benicalap & 0,49 & 0,24 & 0,49 & 0,46 & 0,18 & 0,42 & 0,19 & 0,30 & 0,27 & 0,21 & 0,12 & 0,33 & 0,12 & 0,46 \\
\hline 17. Poblats del nord & & 0,08 & 0,08 & 0,00 & 0,08 & 0,08 & & 0,03 & 0,03 & & 0,08 & 0,08 & $\mathrm{O}, \mathrm{OO}$ & 0,08 \\
\hline 18. Poblats de l'oest & 0,00 & 0,21 & 0,22 & 0,00 & 0,18 & 0,19 & 0,07 & 0,18 & 0,15 & 0,00 & 0,13 & 0,13 & 0,10 & 0,23 \\
\hline 19. Poblats del sud & 0,00 & 0,31 & 0,35 & 0,00 & 0,27 & 0,31 & 0,01 & 0,17 & 0,17 & 0,00 & 0,28 & 0,28 & 0,05 & 0,34 \\
\hline Valencia & 0,48 & 0,35 & 0,49 & 0,46 & 0,29 & 0,44 & 0,17 & 0,26 & 0,23 & 0,20 & 0,18 & 0,38 & 0,08 & 0,46 \\
\hline
\end{tabular}

Fuente: Elaboración propia a partir de datos suministrados por la Consellería d'Educació. 
Para comparar la dimensión de desigualdad de distintos territorios entre sí, resulta más fiable utilizar el índice de Gorard, que nos permite analizar mejor las diferencias entre los diversos distritos de la ciudad y entre titularidades dentro de cada uno de ellos. Los mapas de las figuras 6 y 7 reflejan, respectivamente, la distribución territorial de los valores del índice en las etapas de educación infantil y primaria.

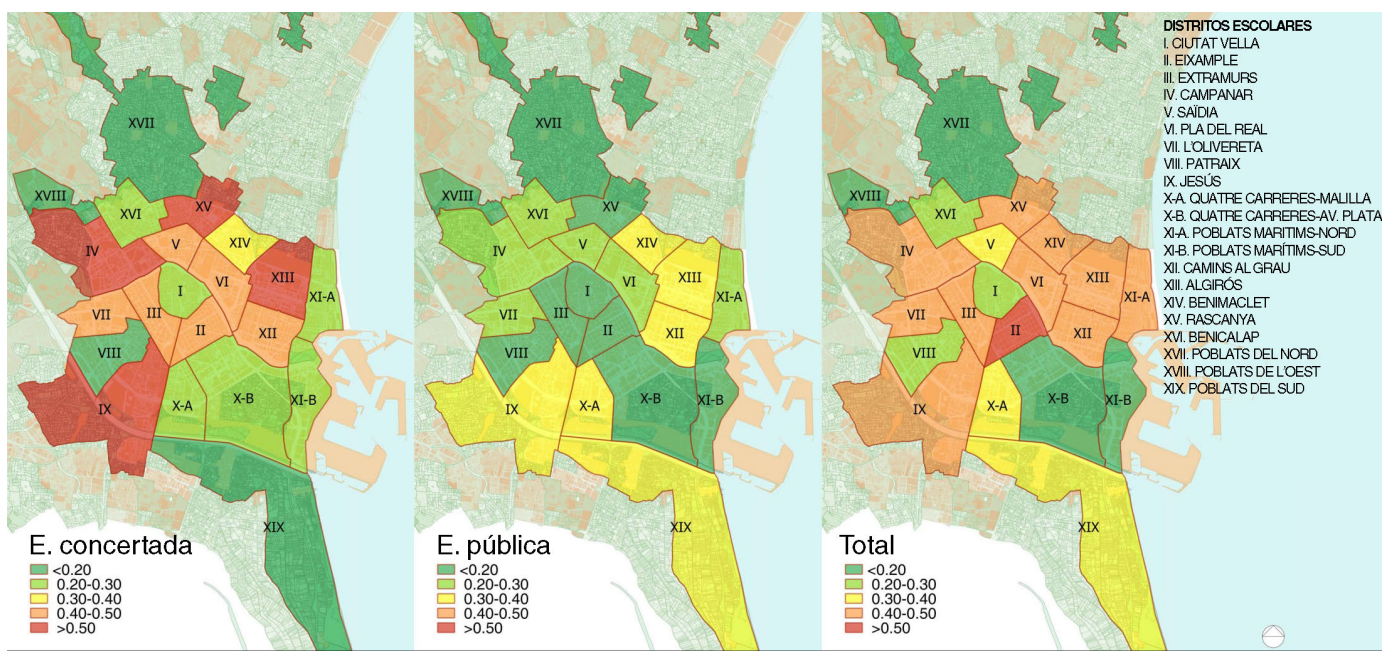

Figura 6. Índices de Gorard en Educación Infantil en los distritos escolares de la ciudad de València

Fuente: Elaboración propia a partir de datos suministrados por la Consellería d’Educació.
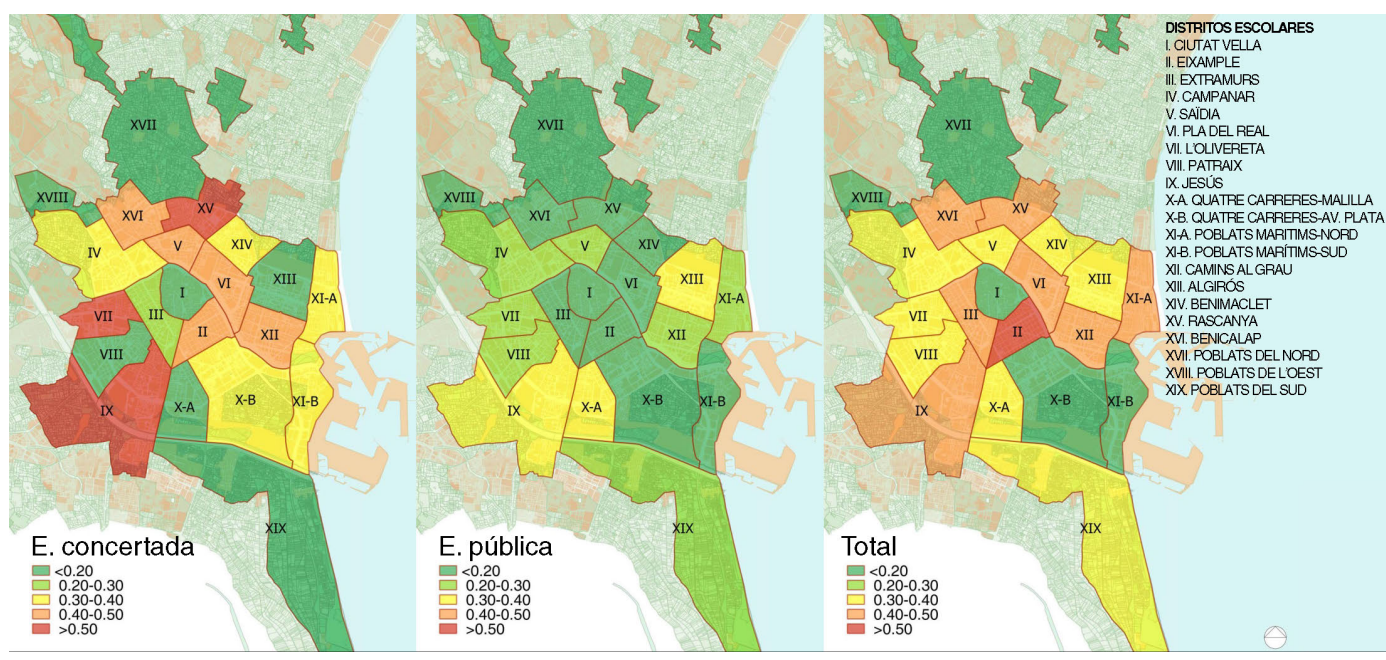

Figura 7. Índices de Gorard en Educación Primaria en los distritos escolares de la ciudad de València

Fuente: Elaboración propia a partir de datos suministrados por la Consellería d’Educació.

Los índices de segregación de los diversos distritos en las dos etapas educativas nos sugieren patrones de segregación diferentes. En la etapa de educación infantil, más de la mitad de los distritos escolares tienen índices de desigualdad escolar altos o muy altos. El patrón en las escuelas concertadas es similar, aunque con desigualdades más acusadas. Sin embargo, no encontramos ningún distrito escolar con alta desigualdad en la distribución de la población extranjera en la escuela pública. En la etapa de educación primaria los índices mejoran ligeramente, con el $43 \%$ de los distritos con alta o muy alta desigualdad. 
En la escuela concertada, la desigualdad es alta o muy alta en el 53\% de los distritos y, de nuevo, no hay ningún distrito en esta situación en la escuela pública.

$\mathrm{Al}$ analizar la dimensión de aislamiento en los diversos distritos escolares, reflejada en los mapas de las figuras 8 y 9 para infantil y primaria, respectivamente, observamos cómo casi la mitad de los distritos tienen índices de aislamiento escolar altos o muy altos en la etapa de educación infantil. Si nos centramos en los centros de titularidad pública, la proporción de distritos escolares es de casi dos tercios, mientras que en los centros concertados disminuye al 15\%. En la etapa de educación primaria los patrones son similares, el $43 \%$ de los distritos escolares presentan índices de aislamiento escolar altos o muy altos cuando tenemos en cuenta los centros de ambas titularidades, la proporción de distritos escolares en esta situación asciende a dos tercios si consideramos únicamente los centros públicos, y desciende al 15\% cuando analizamos el aislamiento escolar del alumnado extranjero en los centros con conciertos educativos.
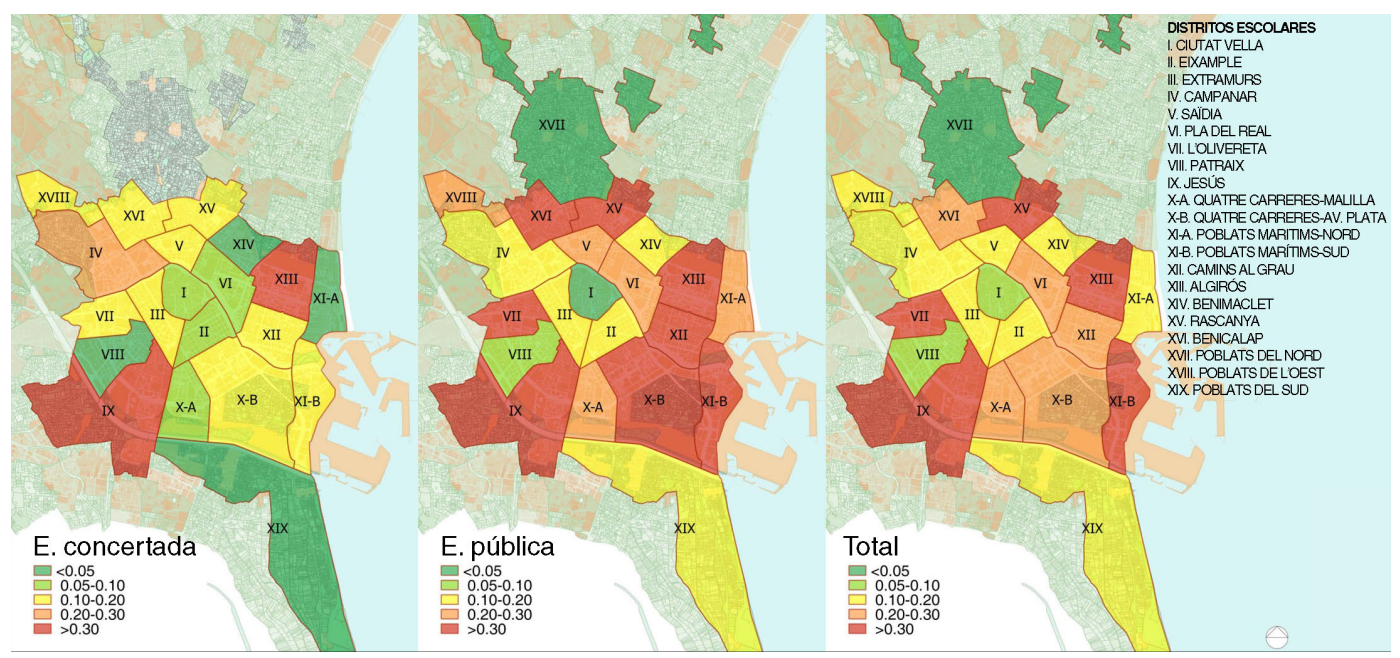

Figura 8. Índices de Aislamiento en Educación Infantil en los distritos escolares de la ciudad de València

Fuente: Elaboración propia a partir de datos suministrados por la Consellería d'Educació.
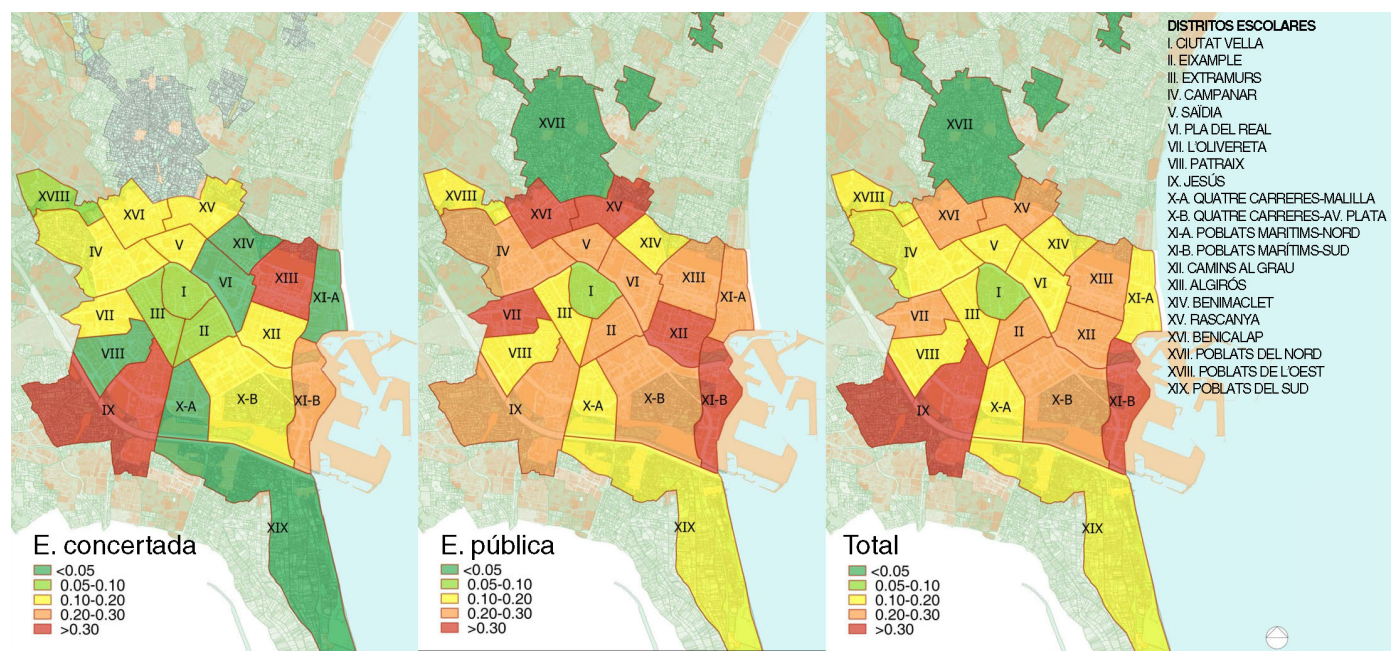

Figura 9. Índices de Aislamiento en Educación Primaria en los distritos escolares de la ciudad de València

Fuente: Elaboración propia a partir de datos suministrados por la Consellería d’Educació. 
El porcentaje de población extranjera residente en los distritos no parece tener mucha influencia en los índices de desigualdad $\left(r=0,11, R^{2}=1 \%\right)$, pero su relación con los índices de aislamiento es considerable $\left(\mathrm{r}=0,62, \mathrm{R}^{2}=38 \%\right)$. La mayor presencia de alumnado extranjero en los centros, lógicamente, tiene una gran influencia en el aislamiento de este colectivo en las aulas $\left(\mathrm{r}=0,84, \mathrm{R}^{2}=71 \%\right)$, sobre todo en las de titularidad pública. Sin embargo, la concentración de alumnado extranjero apenas correlaciona con la dimensión de desigualdad $\left(r=-0,14, \mathrm{R}^{2}=2 \%\right)$. El porcentaje de escuela pública en cada distrito tiene una ligera influencia favorable en los índices de desigualdad $\left(r=-0,37, \mathrm{R}^{2}=14 \%\right)$ pero no en los de aislamiento $\left(r=0,01, R^{2}=0 \%\right)$. Los datos sugieren una mayor relación entre el prestigio que las familias otorgan a los centros y la desigualdad en ellos $\left(r=0,53, R^{2}=\right.$ $28 \%)$.

La descomposición del índice de Hutchens permite observar patrones de segregación escolar diferentes en los diversos distritos de la ciudad y en las dos etapas estudiadas. En los distritos centrales la principal aportación a la segregación la producen los centros concertados, aunque también tiene un impacto considerable la segregación entre titularidades en los distritos donde se ubican los centros escolares de mayor prestigio. En algunos de los distritos periféricos, debido a la menor presencia de centros concertados, la escuela pública tiene una mayor contribución en la segregación. Sin embargo, en los distritos con una escuela concertada más diversa, el mayor peso lo producen los colegios concertados o la segregación entre titularidades.

Los datos indican que el porcentaje de escuela pública en los diversos distritos está relacionado negativamente con el peso de la escuela concertada en la segregación ( $\mathrm{r}=-$ $\left.0,69, R^{2}=47 \%\right)$ y también con la segregación entre titularidades $\left(r=-0,41, R^{2}=17 \%\right)$. Por el contrario, el porcentaje de centros de carácter religioso está relacionado con el mayor peso de la escuela concertada en la segregación $\left(r=0,44, \mathrm{R}^{2}=20 \%\right)$ y con la segregación entre titularidades $\left(\mathrm{r}=0,36, \mathrm{R}^{2}=13 \%\right)$. El número de líneas educativas en los centros también está relacionado con la desigualdad $\left(\mathrm{r}=0,54, \mathrm{R}^{2}=29 \%\right)$ y con la segregación entre titularidades en la etapa de educación primaria $\left(r=0,60, R^{2}=36 \%\right)$.

\section{Conclusiones}

Los resultados nos proporcionan un mapa de la ciudad de València caracterizado por una amplia diversidad de procesos de segregación. En las escuelas se reflejan las diversas segregaciones residenciales de su entorno y aparecen, además, segregaciones de carácter estrictamente escolar que incrementan la desigualdad de oportunidades educativas del alumnado extranjero. Los índices globales de segregación de los sistemas educativos no muestran la diversidad y particularidad de estos procesos.

Podemos afirmar que en la ciudad de València, como en otros contextos territoriales (Valiente, 2008), la desigualdad escolar es mayor en los centros escolares concertados, pero se produce un mayor aislamiento de la población extranjera en las escuelas públicas, tanto en la ciudad en su conjunto como en la mayoría de sus distritos escolares. En conjunto, la desigualdad es también mayor en los distritos centrales que en la periferia, aunque en la escuela pública ocurre lo contrario. El aislamiento es superior en los distritos de la periferia para ambas titularidades.

La segregación que observamos en los centros escolares está condicionada por la desigual distribución de la población en el territorio, pero esta circunstancia tiene una importancia 
menor en la dimensión de desigualdad que en la de aislamiento. Allí donde reside más población extranjera, ésta se encuentra más aislada, y esta circunstancia se refleja también en las aulas de los centros escolares. Sin embargo, las causas principales de la desigualdad escolar del alumnado de origen extranjero en València no parecen estar en su distribución residencial.

La administración educativa no ha apostado por el incremento de la oferta educativa de titularidad pública en el sistema escolar valenciano durante los últimos 25 años, ni por adecuar la oferta a las necesidades escolares de cada sector urbano. Esta circunstancia tiene impacto en la segregación, porque en los distritos con menos escuela pública la desigualdad tiende a ser mayor. También hemos apreciado que donde hay más escuela religiosa y menos escuela pública, la aportación de la escuela concertada a la segregación es mayor y también lo es la segregación entre titularidades. Las autoridades educativas valencianas han primado una política no estratégica y reactiva ante la demanda, aglutinando muchas plazas educativas en determinados centros escolares y facilitando la fuga de población nativa hacia ellos, abandonando las escuelas ubicadas en sus barrios de residencia. El impacto en la segregación escolar de estos desequilibrios entre las diversas zonas se ha constatado también en otros contextos territoriales (Síndic de Greuges, 2016a, p. 65).

Ante estas condiciones estructurales, las escuelas y las familias parecen adoptar posiciones y estrategias que mantienen y refuerzan los procesos de segregación de los alumnos de origen extranjero en los centros escolares de la ciudad. Se observan regularidades entre las diversas entidades titulares de los centros escolares que sugieren mecanismos de selección específicos o corporativos. En la polaridad de los centros religiosos es dónde en mayor medida se conserva la estructura dual de la escuela de la dictadura franquista. En este sentido, las escuelas gestionadas por órdenes religiosas y por sociedades mercantiles son las que en mayor medida parecen anteponer sus propios intereses a los de la sociedad, adoptando medidas que dificultan la escolarización de alumnado extranjero en ellas. Esta circunstancia influye considerablemente en las condiciones de desigualdad de las aulas valencianas.

Ante el proceso de elección de escuela, las familias parecen optar por aquellos centros de mayor tamaño donde, por una parte, la probabilidad de ingreso es mayor y, por otra, el peso de la población extranjera es menor. Los distritos con centros más prestigiosos tienden a ser más desiguales, aunque presentan menor aislamiento del alumnado extranjero en sus aulas. Las familias autóctonas han optado por abandonar las pequeñas escuelas de la periferia en las que la presencia de alumnado de origen extranjero o, sobre todo, de etnia gitana resulta más visible, incrementando las condiciones de desigualdad y aislamiento del conjunto del sistema educativo.

El análisis desarrollado sugiere que en València, como ocurre en otras grandes ciudades españolas (García y Rubio, 2013; López-Falcón y Bayona, 2012; Peláez, 2012), no parece incrementarse la cohesión multicultural. Los datos de escolarización de la población de origen extranjero y los índices de segregación muestran que las escuelas valencianas no están funcionando como mecanismos de integración del alumnado foráneo, que tiende a ser concentrado y, en algunos casos aislado, en ciertas escuelas muy determinadas de la periferia urbana.

Resulta aventurado extraer conclusiones generalizables del estudio de un único caso, pero nuestro análisis indica que la política de incorporar más líneas educativas en los centros 
prestigiosos incrementa la desigualdad en los distritos en los que éstos se ubican y, al mismo tiempo, el aislamiento del alumnado extranjero en los distritos con los centros más desprestigiados por las respuestas familiares que induce. También sugiere que el reparto del grupo minoritario no resulta suficiente para reducir la desigualdad entre centros escolares. El análisis de la construcción del prestigio escolar, las relaciones entre las estrategias familiares ante la elección escolar y el posicionamiento institucional ante esa 'demanda social' deben ayudar a implementar una política que impida la fuga de la población mayoritaria de algunos distritos y su concentración en determinadas escuelas. Ese parece ser el principal reto.

\section{Agradecimientos}

Este artículo ha sido desarrollado en el marco del proyecto de investigación 'Mapa escolar de València: La situación del alumnado y del sistema educativo en la educación obligatoria en la ciudad de València, evolución histórica y formación de estudiantes en esta materia', fruto de un convenio de colaboración entre el Ajuntament de València y la Universitat de València-Estudi General (UVEG) financiado por el Ajuntament de València. Exp: E02 101-2016-000363-00.

\section{Referencias}

Alcalá-Santaella, F., Díaz Orueta, F., Ginés Sánchez, X. y Lourés Seoane, M. L. (2011). Valencia. En M. Iglesias y M. Martí (Eds.), Políticas urbanas en España: Grandes ciudades, actores y gobiernos locales (pp. 201-228). Icaria.

Alegre, M. A. (2017). Politiques de tria $i$ assignació d'escola: Quines efectes tenen sobre la segregació escolar? Fundació Jaume Bofill-Institut Català d’Avaluació de Polítiques Públiques.

Alegre, M. A., Benito, R. y Gonzàlez, I. (2008). Procesos de segregación y polarización escolar: La incidencia de las políticas de zonificación escolar. Profesorado. Revista de Currículum y Formación del Profesorado, 12(2), 1-26.

Alegre, M. A., Benito, R., Gonzàlez, I. y Chela, X., González, S. (2010). Les famílies davant l'elecció escolar. Dilemes $i$ desigualtats en la tria de centre a la ciutat de Barcelona. Fundació Jaume Bofill.

Allen, R. y Vignoles, A. (2007). What should an index of school segregation measure? Oxford Review of Education, 33(5), 643-668. https://doi.org/10.1080/03054980701366306

Avilés Martínez, J. M. (2003). Segregación escolar. En SOS Racismo (Ed.), Informe anual 2003 sobre el racismo en el estado español (pp. 196-204). Icaria.

Ayuntamiento de Vitoria-Gasteiz. (2016). Documento de análisis y propuestas para hacer frente a la segregación escolar en Vitoria-Gasteiz. Ayuntamiento de Vitoria-Gasteiz.

Bell, W. (1954). A probability model for the measure of ecological segregation. Social Forces, 32(4), 357-364. https://doi.org/10.2307/2574118

Benito, R. y Gonzàlez, I. (2007). Processos de segragacio escolar a Catalunya. Fundación Jaume Bofill.

Bonal X. (2012). Municipis contra la segregació escolar. Sis experiències de política educativa local. Fundación Jaume Bofill.

Bonal X. (2018). La política educativa ante el reto de la segregación escolar en Cataluña. UNESCO.

Bonal, X. y Cuevas, J. (2019). Combatre la segregació escolar: De l'amenaça a l'oportunitat. Fundació Jaume Bofill. 
Bourdieu, P. y Passeron, J. C. (1979). La reproducción: Elementos para una teoría del sistema de enseñanza. Laia.

Carbonell i Paris, F. (1998). Les 'escoles gueto' i el dret dels pares a escollir centre educatiu per als seus fills. DCidob, 67, 14-17.

Carbonell, J., Simó, N. y Tort, A. (2002). Magribins a les aules. El model de Vic a debat. Eumo Editorial.

Carrasco, S., Pàmies, J., Ponferrada, M., Ballestín, B. y Bertran, M. (2009). Segregación escolar e inmigración en Cataluña: Aproximaciones etnográficas. EMIGRA Working Papers, 126, 2539.

Coleman, J. S. (1975) Recent trends in school integration. Educational Researcher, 4(7), 3-12. https://doi.org/10.3102/0013189X004007003

Coleman, J. S., Kelly, S. y Moore, J. (1975). Trends in school segregation. 1968-73. The Urban Institute.

Coleman, J. S., Campbell, E. Q., Hobson, C. J., McPartland, J., Mood, A. M., Weinfeld, F. D. y York, R. L. (1966). Equality of educational opportunity. Department of Health, Education and Welfare.

Colom i Ortiz, F. (2011). Desigualtats territorials en l'ensenyament a la ciutat de València (Tesis doctoral). Universitat de València.

Colom i Ortiz, F. (2012). Desigualdades en el sistema educativo no universitario de la ciudad de Valencia. En F. J. García Castaño y A. Olmos Alcaraz (Eds.), Segregaciones y construcción de la diferencia en la escuela (pp. 43-60). Trotta.

Córdoba, C., Farris, M. y Rojas, K. (2017). Discussing school socioeconomic segregation in territorial terms: The differentiated influence of urban fragmentation and daily mobility. Investigaciones Geográficas, 92, 54-76. https://doi.org/10.14350/rig.54766

Cowgill, D. O. y Cowgill, M. S. (1951). An index of segregation based on block statistics. American Sociological Review, 16(6), 825-831. https://doi.org/10.2307/2087511

De Madaria, B., Gabaldón, E., García, S., Muñoz, D., Requena, M., Vila, L. y Rodríguez, J. M. (2018). El proyecto Mapa Escolar de Valencia: Análisis de la zonificación educativa de la ciudad de Valencia. Arxius de Ciències Socials, 39, 131-144.

Duncan, O. D. y Duncan, B. (1955a). A methodological analysis of segregation indexes. American Sociological Review, 20(2), 210-217. https://doi.org/10.2307/2088328

Duncan, O. D. y Duncan, B. (1955b). Residential distribution and occupational stratification. American Journal of Sociology, 60(5), 493-503. https://doi.org/10.1086/221609

Dupriez, V. (2009). La segregació escolar: Reptes socials i politics. Fundació Jaume Bofill.

Duru-Bellat, M. (2004). Social inequality at school and educational policies. UNESCO.

Essomba, M. A. (1999). Política educativa en materia de atención a hijos e hijas de familias inmigradas en Catalunya. En SOS Racismo. (Ed.), Informe anual 1999 sobre el racismo en el estado español (pp. 173-175). Icaria.

Farley, R., Richards, T. y Wurdock, C. (1980). School desegregation and white flight: An investigation on competing models and their discrepant findings. Sociology of Education, 53(3), 123-139. https://doi.org/10.2307/2112408

Fernández Enguita, M. (1999). Alumnos gitanos en la escuela paya. Un estudio sobre las relaciones étnicas en el sistema educativo. Ariel. 
Fernández Soria, J. M. y Mayordomo Pérez, A. (1987). La escolarización valenciana. Tres lecturas históricas. Universidad de Valencia.

Franze, A. (1998). Une école difficile: Sur la concentration d'élèves d'origine immigrée à Madrid. Revue Européenne des Migrations Internationales, 14(1), 105-120. https://doi.org/10.3406/remi.1998.1612

Gaja Díaz, F. (1996). La transformación de Valencia (I). Urbanismo, 28, 78-85.

García Castaño, F. J. y Rubio Gómez, M. (2013). Juntos, pero no revueltos: Procesos de concentración escolar del alumnado extranjero en determinados centros educativos. Revista de Dialectología y Tradiciones Populares, 68(1), 7-31. https://doi.org/10.3989/rdtp.2013.01.001

García Castaño, F. J. Rubio Gómez, M., Olmos Alcaraz, A. y López Fernández, R. (2012). Todos lo sabían... Naturalización de los procesos de agrupación y segregación escolar en un barrio andaluz. En F. J. García Castaño y A. Olmos Alcaraz (Eds.), Segregaciones y construcción de la diferencia en la escuela (pp. 83-118). Trotta.

Gorard, S. y Taylor, C. (2002). What is segregation? A comparison of measures in terms of 'strong' and 'weak' compositional invariance. Sociology, 36(4), 875-895. https://doi.org/10.1177/003803850203600405

Goodman, F. (1972). De facto school segregation: A constitutional and empyrical analysis. California Law Review, 60(2), 275-437. https://doi.org/10.2307/3479538

Grañeras, M., Lamelas R., Segalerva, A., Vázquez E., Gordo J. L. y Molinuevo, J. (1998). 14 años de investigación sobre las desigualdades en el sistema educativo. CIDE

Guryam, J. (2004). Desegregation and black dropout rates. American Economic Review, 94(4), 919943. https://doi.org/10.1257/0002828042002679

Holme, J. J. (2002). Buying homes, buying schools: school choice and the social construction of school quality. Harvard Educational Review, 72(2), 177-206. https://doi.org/10.17763/haer.72.2.u6272x676823788r

Holsinger, D. B. y Jacob, W. J. (2008). Inequality in education. Comparative and international perspectives. Comparative Education Research Centre. https://doi.org/10.1007/978-90481-2652-1

Hutchens, R. (2001). Numerical measures of segregation: Desirable properties and their implications. Mathematical Social Sciences, 42(1), 13-29. https://doi.org/10.1016/So1654896(00)00070-6

Hutchens, R. (2004). One measure of segregation. International Economic Review, 45(2), 555-578. https://doi.org/10.1111/j.1468-2354.2004.00136.x

Instituto de Ciencias de la Educación. (1975). Planificación educativa de la provincia de Valencia. Enseñanza general básica. Universidad de Valencia.

Jenks, C. y Peterson, P. E. (1991). The urban underclass. Brookings.

Katz, I. (1964). Review of evidence relating to effects of desegregation on the intellectual performance of negroes. American Psychologists, 19(6), 381-399. https://doi.org/10.1037/h0040569

López-Falcón, D. y Bayona i Carrasco, J. (2012). Segregación escolar y residencial en Barcelona: Del boom migratorio al asentamiento. En F. J. García Castaño y A. Olmos Alcaraz (Eds.), Segregaciones y construcción de la diferencia en la escuela (pp. 21-42). Trotta. 
Maroy, C. (2008). ¿Por qué y cómo regular el mercado educativo? Profesorado. Revista de currículum y Formación del Profesorado, 12(2), 3-14.

Martínez, L. y Ferrer, A. (2018). Mézclate conmigo. De la segregación socioeconómica a la educación inclusiva. Save the Children España.

Massey, D. S. (1990). American apartheid: Segregation and the making of the underclass. American Journal of Sociology, 96(2), 329-357. https://doi.org/10.1086/229532

Massey, D. S. y Denton, N. A. (1988). The dimensions of residential segregation. Social Forces, 67(2), 281-315. https://doi.org/10.2307/2579183

Massey, D. S. y Denton, N. A. (1993). American apartheid. Segregation and the making of the underclass. Harvard University Press

Murillo, F. J. (2016). Midiendo la segregación escolar en América Latina. Un análisis metodológico utilizando el TERCE. REICE. Revista Iberoamericana sobre Calidad, Eficacia y Cambio en Educación, 14(4), 33-60. https://doi.org/10.15366/reice2016.14.4.002

Murillo, F. J. y Belavi, G. (2018). Segregación escolar de estudiantes pobres en España. Scripta Nova. Revista Electrónica de Geografía y Ciencias Sociales, 22(603), 94-123. https://doi.org/10.1344/sn2018.22.19894

Murillo, F. J. y Martínez-Garrido, C. (2018). Magnitud de la segregación escolar por nivel socioeconómico en España y sus Comunidades Autónomas y comparación con los países de la Unión Europea. RASE. Revista de Sociología de la Educación, 11(1), 37-58. https://doi.org/10.7203/RASE.11.1.10129

Murillo, F. J., Martínez-Garrido, C. y Belavi, G. (2017). Segregación escolar por origen nacional en España. OBETS. Revista de Ciencias Sociales, 12(2), 395-423. https://doi.org/10.14198/OBETS2017.12.2.04

Musset, P. (2012). School choice and equity. Current policies in OECD countries and a literature review. OECD. https://doi.org/10.1787/5k9fq23507vc-en

Nusche, D. (2009). What works in migrant education? A review of evidence and policy options. OECD Publishing. https://doi.org/10.1787/227131784531

Observatorio Social La Caixa. (2016). La educación como ascensor social. Fundación Social La Caixa.

Olmedo, A. y Andrada, M. (2008). La libertad de elección de centro en España: Particularidades nacionales y modalidades locales. Profesorado. Revista de Currículum y Formación del Profesorado, 12(2), 1-8.

Olmedo, A. y Santa Cruz, E. (2008). Las familias de clase media y elección de centro: El orden instrumental como condición necesaria pero no suficiente. Profesorado. Revista de Currículum y Formación del Profesorado, 12(2), 1-30.

Palacio Lis, I. y Ruiz Rodrigo, C. (1993). Infancia, pobreza y educación en el primer franquismo. Valencia 1939-1951. Universitat de València.

Peláez Paz, C. (2012). La escuela, un espacio simbólico que construir: Estigmas y estrategias de los agentes en los procesos de segregación étnica y escolarización. En F. J. García Castaño y A. Olmos Alcaraz (Eds.), Segregaciones y construcción de la diferencia en la escuela (pp. 61-82). Trotta.

Reardon, S. y Owens, A. (2014). 60 years after Brown: Trends and consequences of school segregation. Annual Review of Sociology, 40, 199-218.

https://doi.org/10.1146/annurev-soc-071913-043152 
Reber, S. J. (2005). Court-ordered desegregation: Successes and failures integrating American schools since Brown versus Board of Education. The Journal of Human Resources, 4O(3), 559590. https://doi.org/10.3368/jhr.XL.3.559

Rodríguez-Victoriano, J. M., De Madaria, B., García, S., Vila, L., Muñoz, D., Requena, M. y Gabaldón, E. (2018). Primer informe del programa de investigación: La situación del alumnado y del sistema educativo en la educación obligatoria en la ciudad de Valencia. Universitat de València.

Rodríguez-Victoriano, J. M., De Madaria, B., Gabaldón, E., García, S., Horcas, V., Romero, J. A., Vila, L. y Valero, A. (2019). Segundo informe del programa de investigación 'Proyecto Mapa Escolar'. El mapa escolar de Valencia: Procesos de elección de centro y segregación escolar. Universitat de València.

Rosell, C. H. (1976). School desegregation and white flight. Political Science Quarterly, 90(4), 675695. https://doi.org/10.2307/2148750

Salinas Catalá, J. (2015). Una aproximación a la historia de la escolarización de las gitanas y gitanos españoles. Cabás, 14, 96-126.

Sánchez Hugalde, A. (2007). Inflluencia de la inmigración en la elección escolar. Document de treball 2007/4. Institut d'Economia de Barcelona.

Sánchez Hugalde, A. (2009). La segregació escolar dels immigrants a Catalunya. Quaderns d'Avaluació, 13, 55-76.

Santiago, C. y Maya, O. (2012). Segregación del alumnado gitano en España. Federación Kamira y Fundación Mario Maya

Sanz Arranz, J. R. (1974). Los problemas urbanos de Valencia. En M. Gaviria (Dir.), Ni desarrollo regional ni ordenación del territorio. El caso valenciano (pp. 397-406). Turner.

Síndic de Greuges. (2008). La segregació escolar a Catalunya. Síndic de Greuges de Catalunya.

Síndic de Greuges. (2016a). La segregació escolar a Catalunya (I). La gestió del procés d'admissió d'alumnat. Síndic de Greuges de Catalunya.

Síndic de Greuges. (2016b). La segregació escolar a Catalunya (II). Condicions d'escolarització. Síndic de Greuges de Catalunya.

Tarabini, A., Jacovkis, J. y Montes, A. (2017). Los factores de la exclusión educativa en España: Mecanismos, perfiles y espacios de intervención. UNICEF.

Teixidor de Otto, M. J. (2009). Paisaje urbano y funciones. Historia y ruptura. En J. Hermosilla (Dir.), La ciudad de Valencia. Geografía y arte (pp. 47-68). Universitat de València.

Tenti Fanfani, E. (2008). Nuevos temas en la agenda de la política educativa. Siglo XXI.

Ternes Cordovez, G. (2010). La formación de la periferia urbana de Valencia a partir de los grupos de viviendas (1900-1980). En A. Sanchis, B. Serrano, R. Ternes (Dir.), VLC_GV. Historias vividas: Grupos de viviendas en Valencia 1900-1980 (pp. 79-112). Instituto Valenciano de la Edificación.

Torres, F. (2007). Nous veïns a la ciutat. Els immigrants a València i Russafa. Universitat de València.

Valiente, O. (2008). ¿A qué juega la concertada? La segregación escolar del alumnado inmigrante en Cataluña (2001-06). Profesorado. Revista de Currículum y Formación del Profesorado, 12(2), $1-23$.

Vega Gil, L. (1997). La reforma educativa en España (1970-1990). Educar, 13, 101-128. https://doi.org/10.1590/0104-4060.175 
Wilson, F. D. (1985). The impact of school desegregation programs on white public-school enrollment, 1968-1976. Sociology of Education, 58(3), 137-153.

https://doi.org/10.2307/2112415

Wilson, W. J. (1987). The truly disadvantaged. Inner city, the underclass and public policy. University of Chicago Press.

\section{Breve CV de los autores}

\section{Borja de Madaria}

Es profesor asociado del departamento de Sociología y Antropología Social de la Universitat de València, donde imparte cursos de sociología de la educación. Arquitecto por la Universitat Politècnica de València y Graduado en Sociología por la Universitat de València. Tiene un doctorado internacional en Representaciones Sociales por la Università degli Studi di Roma 'La Sapienza'. Sus intereses de investigación se centran en las representaciones sociales del medio ambiente y el entorno construido, la construcción discursiva del valor patrimonial y la relación entre el contexto urbano y la desigualdad social. Ha coordinado el proyecto de investigación 'Mapa Escolar de València' como técnico de apoyo a la investigación adscrito al ERI-Sostenibilitat de la Universitat de València. ORCID ID: https://orcid.org/OOOO-0002-3546-6666. Email: borja.madaria@uv.es

\section{Luis E. Vila}

Doctor en Economía por la Universidad de Valencia y Visiting Scholar en CERAS (Stanford University) y ROA (Universiteit Maastricht). Catedrático de métodos cuantitativos para la economía y la empresa en la Universidad de Valencia, donde imparte cursos de Economía de la Educación y Métodos Cuantatitativos. Su actividad investigadora y de transferencia se orienta hacia la evaluación econométrica de los efectos socioeconómicos de las inversiones educativas y la comprensión los efectos de la acumulación de capital humano heterogéneo en el status laboral de los individuos. Forma parte del equipo de investigación del proyecto 'Mapa Escolar de València'. ORCID ID: https://orcid.org/o000-0002-9541-9300.Email: luis.vila@uv.es 